\title{
Review Article \\ Dysfunction of Lacrimal and Salivary Glands in Sjögren's Syndrome: Nonimmunologic Injury in Preinflammatory Phase and Mouse Model
}

\author{
Toshiharu Hayashi \\ Laboratory of Veterinary Pathology, Faculty of Agriculture, Yamaguchi University, 1677-1, Yoshida, Yamaguchi 753-8515, Japan \\ Correspondence should be addressed to Toshiharu Hayashi, hayasi@yamaguchi-u.ac.jp
}

Received 13 October 2010; Revised 8 February 2011; Accepted 8 March 2011

Academic Editor: Oreste Gualillo

Copyright (C) 2011 Toshiharu Hayashi. This is an open access article distributed under the Creative Commons Attribution License, which permits unrestricted use, distribution, and reproduction in any medium, provided the original work is properly cited.

\begin{abstract}
Sjögren's syndrome ( $\mathrm{SjS}$ ) is a chronic autoimmune disorder characterized by dry eyes and dry mouth due to dacryoadenitis and sialoadenitis with SS-A/Ro and/or SS-B/La autoantibodies in genetically predisposed individuals. Destruction of lacrimal and salivary glands by autoimmune reactions may lead to clinical manifestation. However, the mechanisms behind the decreased volume of secretions in tears and saliva are complex and are not fully understood. Exocrine gland dysfunction may precede autoimmunity (acquired immunity) or represent a process independent from inflammation in the pathogenesis of SjS. The preceded functional and morphologic changes of those tissues by nonimmunologic injury before the development of inflammation at the sites of target organs have been implicated. This paper focuses on the several factors and components relating to glandular dysfunction and morphologic changes by nonimmunologic injury during the preinflammatory phase in mouse model, including the factors which link between innate immunity and adaptive immunity.
\end{abstract}

\section{General Introduction of SjS}

1.1. pSjS and sSjS. Majority of patients with SjS are women, and the diagnosis is usually done when they are $40-50$ years old [1]. SjS primarily affects women and may occur as an isolated disorder, which is termed as primary SjS (pSjS), or it may occur in association with recognized collagen diseases, such as rheumatoid arthritis (RA), systemic lupus erythematosus (SLE), and other collagen diseases, termed as secondary SjS (sSjS) $[2,3]$. Although the clinical manifestations of pSS patients are mainly those of an autoimmune exocrinopathy, almost half of patients develop extraglandular disease and confer increased risk (approximately 5\% of patients with $\mathrm{pSjS}$ ) for lymphoma (B cell non-Hodgkin's lymphoma) development $[4,5]$. pSjS involves muscular, respiratory, gastrointestinal, renal, hepatic, pancreatic, peripheral, central nervous, and lymphoid tissues [6,7].

\subsection{Triggering Factors in $p S j S$ and sSjS}

1.2.1. Gene. Like other autoimmune diseases, relationship between HLA alleles and SjS pathogenesis has been suggested $[8,9]$. Polymorphisms of the interferon regulatory factor
5(IRF-5), a gene implicated in type I IFN secretion after stimulation of innate immunity and in type 1 IFN signal transduction, are associated with disease susceptibility in pSjS $[10,11]$. Copy number variants of two relevant to immune regulation genes such as $\mathrm{F} c \gamma$ receptor $3 \mathrm{~B}$ (FCGR3B) and $\mathrm{CC}$ chemokine ligand 3-like 1 (CCL3L1) contribute to susceptibility to autoimmune diseases such as SLE and pSjS [12].

1.2.2. Hormone. Hormonal unbalance may be one of the major triggering factors behind the syndrome of SjS and the increased risk is due to a change in the androgen-estrogen ratio and sex steroids including lack of androgens influence both at the systemic (fatigue) and local (exocrine glands) level [13]. As the peak age of onset in SjS occurs around menopause characterized by a decrease in estrogens, and ovaries produce low levels of testosterone, which decrease at the time of menopause $[14,15]$. The other significant source of androgens is the adrenal cortex, which produces dehydroepiandrosterone (DHEA) and its metabolite DHEA sulfate (DHEA-S) [14, 15]. Other than the triggering effects of hormone, influence of androgens and pituitary hormones on the structural profile and secretory activity 
of the lacrimal gland has been suggested [16]. Tzioufas et al. [17] reported that the hypothalamic-pituitary-adrenal (HPA) axis appears to be disturbed, since significantly lower basal adrenocorticotropic hormone (ACTH) and cortisol levels were found in patients with SjS. The hypothalamicpituitary-gonadal (HPG) axis is also involved, since lack of estrogens is associated with human disease and the development of autoimmune exocrinopathy in several experimental models. Moreover, exocrine glands are enriched with neuroendocrine-related molecules. Psychological disturbances can be very well explained by mechanisms directly related to disturbances of the neuroendocrine axis. Apart from functional changes, the syndrome is also characterized by structural abnormalities of the secretory acinar apparatus, and patients with SjS show low serum DHEA levels, which may lead to acinar cell degeneration, and an autoimmune attack directed against exocrine glands and nuclear autoantigens may occur [18].

1.2.3. Pathogen. Among various environmental factors viral infections may act as a trigger before the development of inflammation [19] or may be involved during the process of immune reactions [20]. Several viruses such as EpsteinBarr virus (EBV; types 1 and 2) [21,22] and hepatitis $\mathrm{C}$ virus, retroviruses such as human T-cell lymphocytic virus type 1 (HTLV-1) [23], and endogenous retroviruses such as a HERV-K113 [24] have been found to be closely associated with the patients with $\mathrm{pSjS}$ and sSjS. Also, the incidence of keratoconjunctivitis sicca is increased in patients with exogenous retroviruses like immunodeficiency virus infection [25]. Expressed HERV-encoded proteins, which would be considered as foreign antigens, result in production of antibodies against them in patients. These lead to cross-reaction with the components of the body such as between ribonucleoprotein $(\mathrm{Sm})$ and HERVs [20], or between lipocalin/ $\alpha$-fodrin and EBV [26] via structural or functional molecular mimicry [27]. Also, bacteria can activate innate immune responses interacting with Tolllike receptors (TRLs) that recognize pathogen-associated molecules, resulting in a prolonged inflammatory response that may occur and lead to chronic inflammation with activation of adaptive immune responses [27]. Alternatively, some infectious agents such as malaria, Toxoplasma gondii, and Helicobacter(H.) pylori may have a protective effect in SLE [27]. In contrast $H$. pylori may contribute to the pathogenesis in SjS [28]. In addition, epidemiological and experimental data suggest that infections or the exposure to nonpathogenic bacteria protect individuals from developing some autoimmune and atopic disorders [29].

\subsection{Acquired Immunity in SjS}

1.3.1. Cellular Immunity. A progressive loss of exocrine gland function due to glandular damage is induced by a lymphoid cell infiltration into these target organs. The autoimmune character of the disease and diagnosis in patients with SjS are made by focal lymphocytic sialoadenitis in minor salivary glands with a focus score $>1$, defined as a number of lymphocytic foci (which are adjacent to normal-appearing mucous acini and contain more than 50 lymphocytes per $4 \mathrm{~mm}^{2}$ of glandular tissue) with positive test for SjS autoantibodies (SS-A/Ro and SS-B/La) in the serum [30]. Histopathology usually exhibits lymphocytic infiltration, with the majority of lymphocytes being $\mathrm{CD} 4^{+} \mathrm{T}$ cells in the minor salivary gland lip biopsy from SjS patients in accompanying $B$ cells $[5,6,31]$. Infiltrated lymphocytes are composed of mainly autoreactive $\mathrm{CD}^{+} \mathrm{T}$ cells [32], $\mathrm{CD}^{+} \mathrm{T}$ cells, and dendritic cells, and macrophages are also present, and $\mathrm{T}$ cells preferentially express the T-cell receptor (TCR)V $\beta 6$ and TCRV $\beta 8$ in these tissues in an animal model [33]. In human lymphocytes consisting of $\mathrm{T}$ and $\mathrm{B}$ cells in the salivary gland lesions has been reported $[34,35]$. Various studies indicate that human minor salivary gland biopsy tissue and salivary glands from mouse models exhibited helper $\mathrm{T}(\mathrm{Th}) 1$ type cytokine profiles at the sites of target organs. For example, in labial salivary gland of human patients with SjS interleukin (IL)-2 and interferon (IFN)- $\gamma$ mRNAs were consistently detected, whereas IL-4 and IL-5 mRNAs were detected in some cases associated with strong B cell accumulation, suggesting Th1 cells are essential in the induction and/or maintenance of SjS, while Th2 cells are involved in the progression of the disease process, especially in local B cell activation [36]. Moreover, it has been reported that $\mathrm{CD} 4^{+} \mathrm{T}$ cells in salivary glands expressed large amounts of IFN- $\gamma$ mRNA, whereas those cells produced little IL-4 and IL-5 mRNAs in SjS patients [37]. Also lymphocytes infiltrating in the labial salivary glands of patients with $\mathrm{pSjS}$ or sSjS are capable of producing both Th1 and Th2 cytokines, and the balance between them shifts in favor of Th1 responses in large salivary glands with high infiltration score [38]. An increase in several proinflammatory cytokines (mRNAs expression), including interleukin(IL)- $1 \beta$, tumor necrosis factor (TNF)- $\alpha$, IL-6, IL7, IL-10, IFN- $\gamma$, and inducible nitric oxide synthase (iNOS) was demonstrated in the submandibular glands of nonobese diabetes (NOD) mice, which are originally reported as a model for insulin-dependent diabetes mellitus, a model for pSjS with lymphocytic infiltrates [33]. Also, cytokine mRNA detected in lacrimal tissue was similar to that seen in the submandibular glands but appeared both earlier and more intensely [33]. Distinct subset of $\mathrm{CD} 4^{+}$memory effector $\mathrm{T}$ cells such as Th17 cells may play an important in various autoimmune diseases, including SjS [39-42]. Moreover, IL23/Th17 pathway has been implicated in SjS pathogenesis in Ro52-null mice, which develops systemic autoimmune disease resembling human lupus [43].

1.3.2. Humoral Immunity. Autoantibodies may also play a role in the pathogenesis. Serologically, the presence of rheumatoid factor, hypergammaglobulinemia, and antibodies to nuclear protein, such as SS-A/Ro and SS-B/La [44] as well as antibodies against $\alpha$-fodrin [45], carbonic anhydrase II [46], and acetylcholine muscarinic 3 receptor [47] have been observed in the sera of SjS patients. The later could play a pivotal role in secretory function in $\mathrm{pSjS}$ [48]. In addition, there is a possibility that cryptic antigens recognized by $\mathrm{T}$ lymphocytes and antibodies in autoimmune pathogenesis including SjS [49]. 


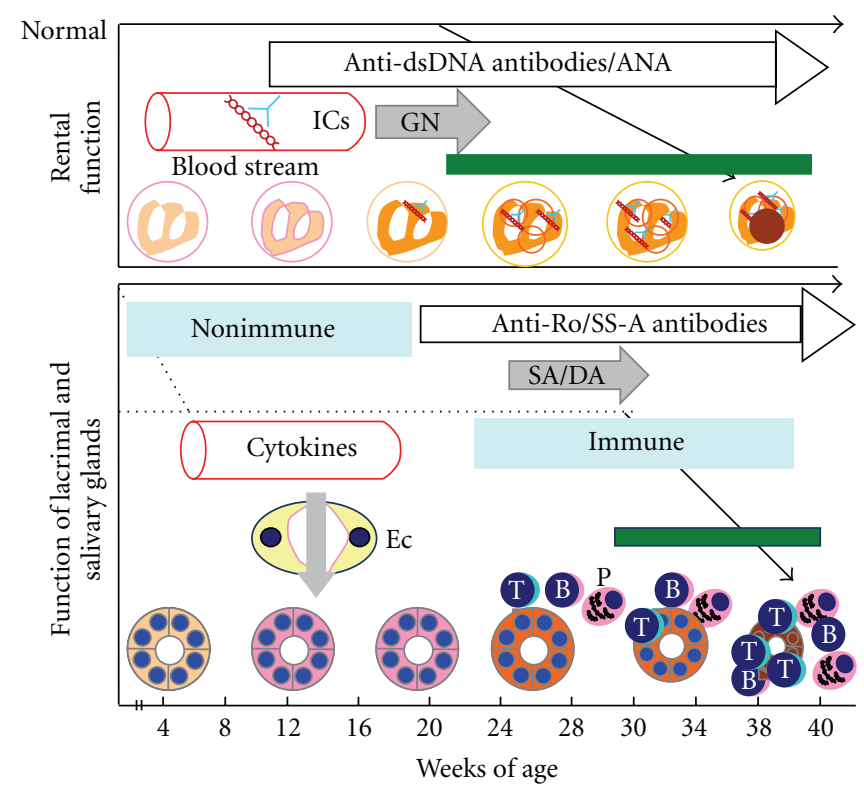

FIGURE 1: Hypothetical relationship between nonimmune (preinflammatory) phase and immune reaction (acquired immunity). Female $\mathrm{B} / \mathrm{WF}_{1}$ mice, a model for SLE and sSjS, develop several autoantibodies (e.g., anti-dsDNA and antinuclear antibodies: ANA) from younger ages (approximately 12 weeks of age) and thereafter immune-complexes- (ICs-) mediated glomerulonephritis (GN) develops with age, leading to overt disease (renal failure). On the other hand, production of anti-Ro/SS-A antibodies begin at the age of 20 weeks of age and dacryoadenitis and sialoadenitis (SA/DA) may develop in salivary and lacrimal glands. During the nonimmune phase, abnormal function and morphology of these tissues such endothelial cells (Ec) may permit leak of cytokines produced systemically. Dotted line shows hypothetical functional defect. Green lines may indicate clinical manifestation (self-reported symptoms) in human patients with sSjS. In this figure, the regenerative changes of acini components are not shown. T cell (T), B cell (B), and plasma cell (P).

\section{Nonimmunologic Injury in Preinflammatory Phase in SjS}

2.1. Background. A number of references are increasing in immune-mediated pathogenesis of SjS. On the other hand, there are a few reports on nonimmunologic injury relating to glandular dysfunction before inflammation. Although the fluid secretory impairment of lacrimal and salivary glands in SjS is thought to be related to the extent of lymphocytic infiltration and subsequent loss of glandular tissue, lymphocyte infiltration alone is not sufficient to explain the secretory dysfunction in the female $\mathrm{NZB} / \mathrm{W}\left(\mathrm{B} / \mathrm{WF}_{1}\right)$ mouse, a model for sSjS and SLE, since less fluid secretion in the young $\mathrm{B} / \mathrm{WF}_{1}$ females compared to C57/6 control mice was observed before the development of inflammation in lacrimal glands [50] (Figures 1 and 2). Also, it has been suggested that the decrease in salivary flow follows the occurrence of focal lymphoid infiltration, with a considerable delay in time, and that the sole destruction or replacement of glandular tissue by inflammatory cells is not sufficient to explain the severe impairment in salivary secretion [51]. In addition, Deshmukh et al. [52] reported that in the initial stages of the disease gland dysfunction did not correlate with the severity of lymphocytic infiltration/foci in the salivary gland and that autoantibodies to salivary gland antigens or Ro60 may not play a major role in the induction of gland dysfunction in female $\mathrm{B} / \mathrm{WF}_{1}$ mice. Jonsson et al. [51] indicated at least 2 phases of SjS-like disease in female NOD mice, where hyposalivation was preceded by inflammatory changes in the salivary glands, whereas abrupt changes in secretion occurred without significant progression of inflammation. Moreover, submandibular gland histology revealed selective loss of acinar tissue with decreased tear volume despite an absence of sialoadenitis in NOD-scid mouse, which lacks T and B cells [53]. Rosignoli et al. [54] reported a progressive loss of nitric oxide synthase activity in submandibular and parotid glands started at 12 weeks of age without inflammation and paralleled the decline in salivary secretion in NOD mice, and this defect was associated with a lower response to vasoactive intestinal peptide in salivary flow rate, cAMP, and nitric oxide/cGMP production. Their data suggest that early stages are characterized by defective neurotransmittermediated signaling in major salivary glands that precedes the autoimmune response. In $\mathrm{B} / \mathrm{WF}_{1}$ mice incomplete Freund's adjuvant accelerated glandular hypofunction, and this was associated with sialoadenitis but without evidence of robust adaptive autoimmune response in the early stages of the disease [52].

2.2. Animal Model for Pathogenesis in SjS. As mentioned above, the immunopathogenesis of SjS is complex with different intricate factors, including triggering factors such as hormone, disease susceptibility gene especially major histocompatibility complex (MHC), endogenous virus, and exposure of cryptic antigens. Moreover, the delay in the appearance of symptoms (self-reporting symptoms) and 


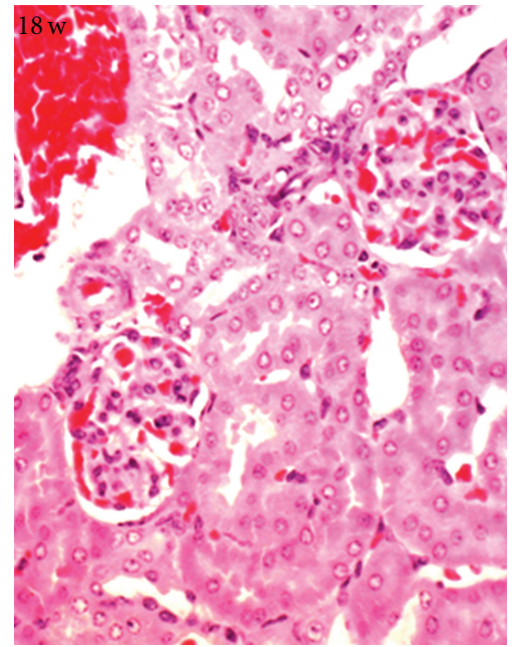

(a)

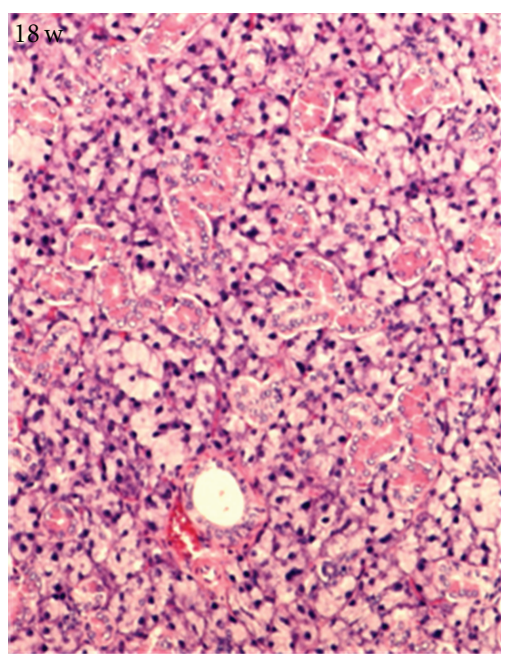

(d)

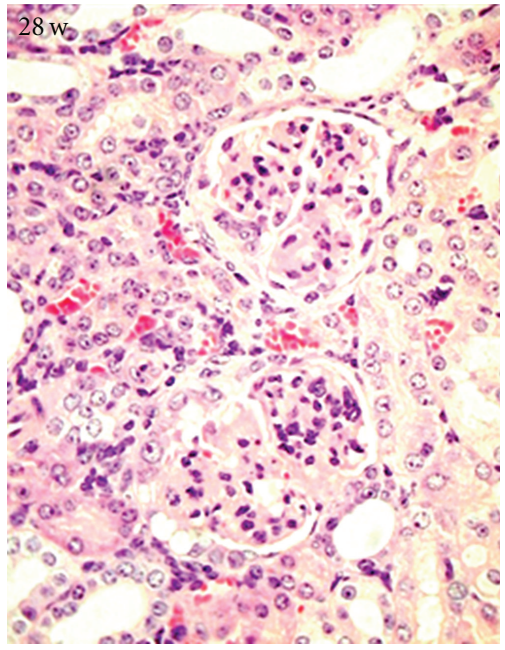

(b)

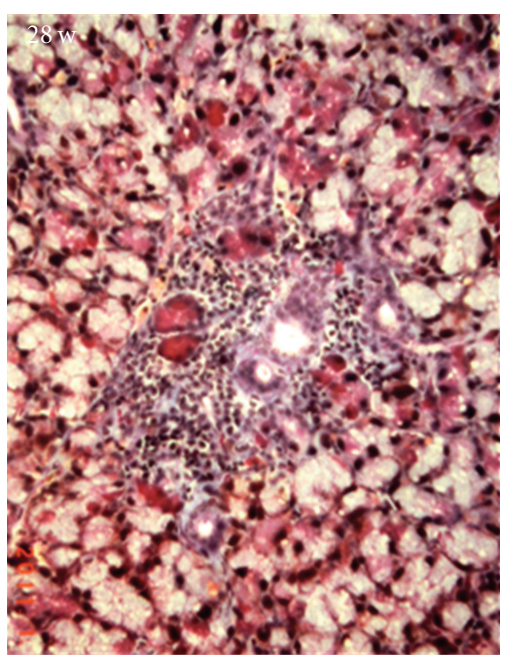

(e)

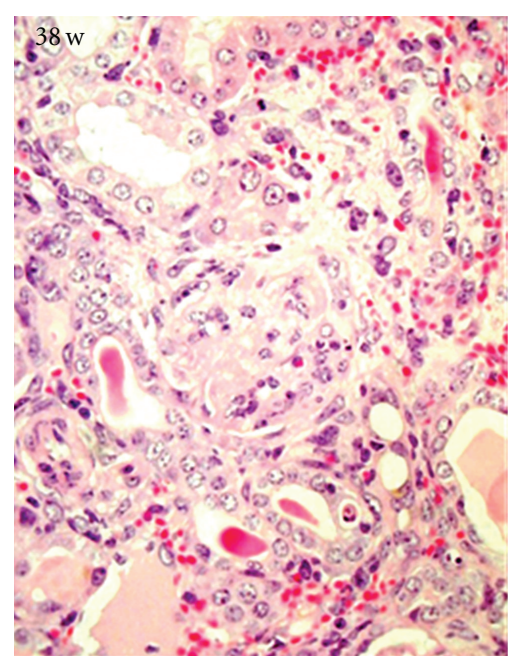

(c)

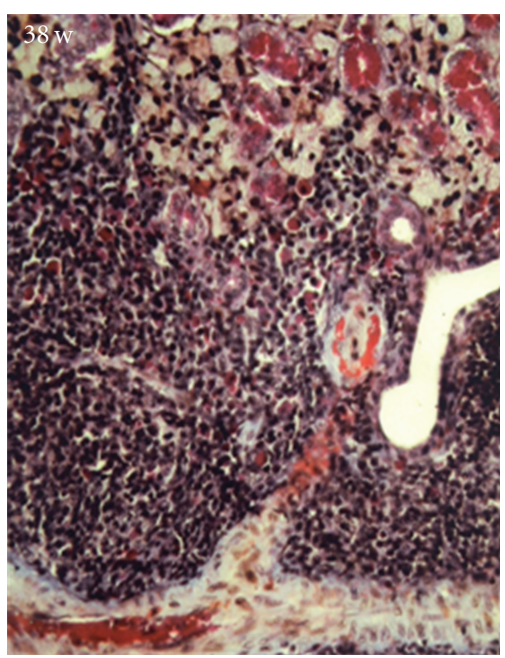

(f)

Figure 2: Dysfunction of renal function due to glomerulonephritis may precede glandular dysfunction. Glomerulonephritis in different ages of female $\mathrm{B} / \mathrm{WF}_{1}$ mice. Slight increase of mesangial cells (a), diffuse thickening of basement membranes with segmental proliferation of mesangial cells (b), and sclerosing change (c) in glomeruli are visible. On the other hand, relatively normal structure in submandibular gland is seen (d), but at this time dysfunction of glands is reported [50]. Focal lymphoid cell infiltration (e), and dense infiltration (f) are visible. Samples were obtained survived mice ( $a, b, d$, and e), whereas those were from dead mice (c and f). HE: (a-d). Azan: (e) and (f).

due to ethical issues, it is very difficult to study the wide array of factors interaction in the pathogenesis (especially nonimmunologic injury) of SjS in human patients [31]. To solve this problem, different animal models have been elaborated for studying the different subsets of the aspects of the physiopathology of this disease. This review focused on nonimmunologic injury before the development of inflammation (acquired immunity) at the site of lacrimal and salivary glands in relation with glandular dysfunction.

\section{Discussion of Previous Research in SjS}

Apoptosis, nonapoptosis, and abnormal distribution/expression of aquaporin before the inflammation will be introduced. Effects of systemic factors (IFN- $\alpha$ [55], complement, and cytokines) on components of target organs (autonomic nerve, tight junction and basement membrane) due to nonimmunologic injury will be also included (Figure 3 ). Hormonal effects on glandular function is stated in the section of basement membrane.

3.1. Apoptosis. Classically, the pathogenesis of SjS proposed in explaining glandular hypofunction is a two-step mechanism. At first, a primary immune attack by infiltrating lymphocytes and at second cytotoxic cell death (necrosis) and apoptosis, which may be one of factors relating with dysfunction of salivary and lacrimal glands, in genetically predisposed individuals may occur [56]. In this section, some reports of apoptosis induced probably by genetic abnormality including the role of apoptosis as initiator will 


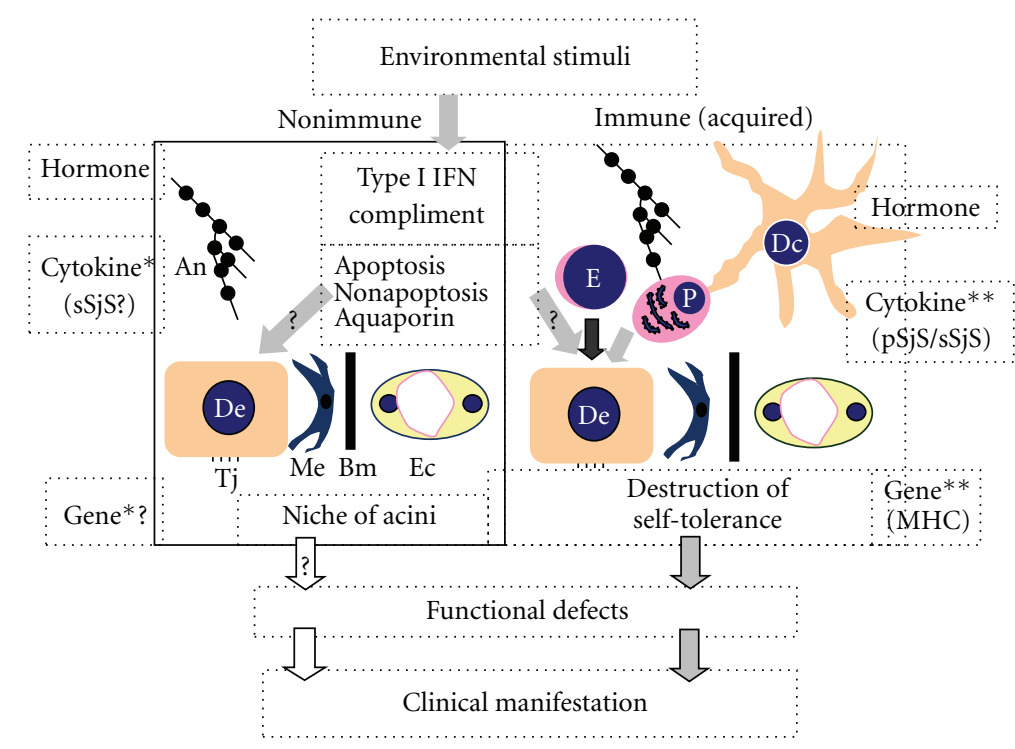

Figure 3: Probable factors and causes (?), which may affect function and structure in lacrimal and salivary glands in nonimmune injury (Hypothesis). Environmental factors (especially viruses and bacteria) may play a role in both nonimmune and immune mechanisms. Selfreporting symptoms in patients with SjS may be the results of cumulative effects of nonimmune and immune mechanisms. Apart from functional changes, the syndrome may be also characterized by structural abnormalities of microenvironmental components (niche) which include endothelial cells (Ec) in capillary, myoepithelium (Me), nervous fibers (An), basement membranes (Bm), tight junction (Tj), duct (De), and secretory acinar epithelial cells. In addition, dendritic cells (Dc), which appear in pSjS patients but not in healthy controls [55], may play an important role in immune attack together with effectors (E). Effect of circulating cytokine* and gene* in nonimmune phase and role of locally produced cytokine ${ }^{* *}$ and abnormal gene ${ }^{* *}$ being responsible for destruction of self-torerance in immune phase are indicated. In this figure, detailed immune mechanisms including the role of environmental factors are omitted. E: effector cells (e.g., cytotoxic T cell, Th1 cell, B cell, and plasma cell).

be introduced. Also, opposite opinions against apoptosis in general pathogenetic roles are included.

It has been demonstrated using NOD mice and NODscid (immunodeficient) mice that the pathogenesis of SjS occurs in two phases: an asymptomatic phase epithelial cells of exocrine tissues undergo dedifferentiation accompanied by elevated apoptosis and a second phase in which autoimmunity is mounted against target organ autoantigens, resulting in the activation of T- and B-cells, and the generation of autoantibodies [32]. Humphreys-Beher et al. [57] reported that genetic alterations in glandular homeostasis involving the death program may contribute to disease progression or even in the initial trigger of autoimmunity, since there are high levels of apoptosis and aberrant protein expression in the submandibular gland in the absence of an immune response in NOD mice. Kong et al. [58] demonstrated that apoptosis of the secretory epithelial cells occurs in both NOD and NOD-scid mice in salivary and lacrimal glands in which Fas protein and mRNA were expressed only in the exocrine glands before inflammation in NOD and NOD-scid mice, but not in normal BALB/c mice. A potential apoptotic process dependent on Fas/Fas ligand (FasL) interactions occurring in NOD-scid glandular secretory epithelial cells strongly suggests the apoptosis may precede lymphocytic infiltration [58]. Qi et al. [59] reported that apoptosis may be initiator of inflammation in target organs in which lacrimal dysfunction was found in the early age without inflammation in NOD mice, and apoptotic cells exist in acinar epithelium at 5 weeks of age, but not 2 weeks of age without inflammatory foci in submandibular glands. If that is the case, apoptosis may be induced genetically as well as immunologically. The relationship between apoptosis and dysfunction of glands in NOD-scid mice is unclear. Apoptosis before inflammation in human SjS is not known.

3.2. Nonapoptosis. Apoptosis of the epithelial cells in the salivary glands has been shown to be a rare event [60]. Many patients with SjS who have little or no glandular function (as evidenced by markedly diminished or absent saliva output) retain large amounts of normal-appearing acinar tissue in their salivary glands [61]. This residual tissue is functional in vitro $[62,63]$, although they show a reduced sensitivity to muscarinic stimulation [63]. Van Blokland et al. [64] reported that before and after the onset of sialoadenitis in NOD and NOD-scid mice, numbers of apoptotic cells were not increased as compared with control mice at any age. Expression of B-cell leukemia/lymphoma-2(bcl-2), which is known as an antiapoptotic molecule by prohibiting cytochrome $\mathrm{c}$ release from mitochondria and neutralizing the function of apoptosis inducer Bax [65] on submandibular gland epithelial cells as early as 3 days of age increased, and low-level expression of Fas and FasL mRNA was observed in NOD and NOD-scid mice from 1 day of age onward [64]. Nonapoptosis mechanisms before inflammation do not deny 
the role of apoptosis during the process of inflammation, since there are a number of references that apoptosis may play an important role in the pathogenesis of SjS [66], but there is a possibility of non-apoptotic mechanisms during the process of the disease.

Using a non-apoptotic model for glandular hypofunction, Dawson et al. [66] have suggested that interaction between the immune system and the secretory process could lead to glandular hypofunction such as inhibition of neurotransmitter release by cytokines, enhanced breakdown of ACh by increased levels of cholinesterase, blockade of M3R by antimuscarinic autoantibodies, and altered expression or distribution of aquaporin5.

3.2.1. Aquaporin. Fundamental importance of aquaporins by their conservation from bacteria through plants to mammals has been suggested, and ten mammalian aquaporins (AQPs) identified are expressed in several organs (e.g., the kidney, lung, eye, and brain) and multiple water-channel proteins that regulate the movement of water through the plasma membrane of secretory and absorptive cells in response to osmotic gradients [67]. Homologs are expressed in each with a distinct distribution, providing a network for water transport in those locations [67]. In this section, at first normal distribution/expression of AQPs in healthy human and animals will be mentioned. Also abnormal distribution/expression of AQPs from human SjS, who may have inflammation, and then data from mice will be introduced.

Abnormal distribution and expression of AQP5 in acini of salivary glands are likely to contribute to the deficiency of fluid secretion during the noninflammatory phase but also during the immunologic phase. Delporte [68] reviewed the normal presence of AQP1 (apical and basolateral membranes of endothelium and myoepithelium of rat and human), AQP3 (basolateral membranes of acinar in human), AQP4 (basolateral membranes of duct in rat), AQP5 (apical membranes of acinar in rat and human, basolateral in acinar or secretory granules in rat), AQPs 6 and 7(unknown), and AQP8 (cytoplasm of myoepithelium in rat) in salivary glands. Recently, it has been reported in more details that AQP5 appeared mainly at the apical membrane of mucous glands, basolateral membrane, and basal membrane of serous acini including intense staining in the intercalated ducts, striated ducts, and secretory ducts of the labial gland in healthy volunteers, whereas AQP5 was distributed at the basal membrane and obviously reduced at the apical membrane in patients with SjS [69]. The presence of AQP1, AQP5, and AQP8 has been generally accepted by many, while the presence of AQP3, AQP4, AQP6, and AQP7 still remains controversially [68]. Among AQPs, AQP5 seems to be the only AQP playing a major role in the salivary secretion process and its expression was higher at the basal membrane, and lower at the apical membrane of acinar cells of salivary gland in pSjS [70]. In contrast, AQP5 is normally present in the apical membrane of acinar cells, whereas expression of AQP-1 in myoepithelial cells, but not in endothelial cells of capillaries, was decreased by $38 \%$ in pSS glands. Patients with pSjS or sSjS showing high \% reactivity of acinus area with $\mathrm{AQP} 5$ revealed AQP5 primarily at the basal membranes of the acinus, whereas in patients with low $\%$ of acinus area AQP5 was detected at the apical membrane of acinar cells of salivary gland in patients with pSjS [71]. Tsubota et al. [72] reported cytoplasmic AQP5 was seen in patients with SjS. Beroukas et al. [73] reported that in patients with $\mathrm{pSjS}$ density of AQP5 in salivary glands does not differ between patients with pSjS and normal controls. This discrepancy in human might be because of differences between salivary and lacrimal glands, between populations of patients [54], between pSS and sSS, or between different disease stages. Groneberg et al. [74] suggested that tissuespecific differences, or different techniques might affect the results. Abnormal distribution/expression of AQP5 in acinar epithelium of minor salivary glands lacking inflammatory cell infiltration was observed, suggesting that their abnormal expression may not be due to only direct inflammatory cell reaction, even in the inflammatory phase [68].

By the comparative study between $\mathrm{AQP}^{+/+}$mouse and AQP5 knockout $\left(\mathrm{AQP5}^{-/-}\right)$mouse AQP5 was localized mainly in the ductal cells rather than in the acinar cells of the lacrimal gland without decreased tear secretion, whereas in the parotid gland AQP-5 was observed abundantly in acinar cells, but not in ductal cells, with reduced saliva secretion [75]. In addition, Krane et al. [76] reported that water permeability decreased by $65 \%$ in parotid and $77 \%$ in sublingual acinar cells from $\mathrm{AQP}^{-/-}$mice in response to hypertonicity-induced cell shrinkage and hypotonicityinduced cell swelling. These data show that AQP5 is the major pathway for regulating the water permeability in parotid and sublingual acinar cells (a critical property of the plasma membrane which determines the flow rate and ionic composition of secreted saliva). Moore et al. [77] provided the evidence that AQP5 in the apical membranes of acinar and duct cells, AQP3 and AQP4 in the basolateral membranes of acinar cells, and AQP1 in microvascular endothelial cells in lacrimal glands in transgenic mice lacking water channels AQPs. No decrease in tears in knockout mice lacking AQP1, AQP3, AQP4, and AQP4 against an essential role for AQPs in lacrimal gland secretion was observed [77]. Soyfoo et al. [78] reported that the 8-week-old female NOD mice without inflammation and normal age-matched $\mathrm{BALB} / \mathrm{c}$ (normal) mice showed a similar distribution of AQP5 primarily at the apical membrane of the salivary gland acini, whereas in acini from the submandibular glands (but not from the parotid glands) from 24-week-old NOD mice with inflammation, AQP5 staining was reduced at the apical membrane but was increased at the basal membrane compared to normal mice, in which a significant decrease in pilocarpine-stimulated salivary flow was observed. On the other hand, Nishimura et al. [79] reported that AQP5 was expressed in the apical and lateral cell membranes of acinar cells in the parotid and submandibular glands of normal mice, but not in the sublingual glands, whereas AQP5 was expressed not only in the cell membranes of acinar cells in the apical domains but also in the cytoplasm in the female MRL/lpr mouse, a model for not only RA-like disease but also sSjS in human. There are some differences in distribution/expression of AQPs. Thus, it has been pointed out that the hypothesis that AQP5 has a major role in the 
pathogenesis of pSS needs to be reassessed and unconfirmed issue has to be determined [80].

However, accumulating evidence suggests that abnormal AQP5 expression/distribution in acini epithelium of salivary (especially submandibular) glands, at least, may contribute to hyposalivation at some extent before inflammation.

3.3. Type I Interferon $(I F N \alpha / \beta)$. Role of cytokines will be mentioned later, but Type I IFN will be introduced in this section from the point of innate immunity before the development of immune reaction. Regarding the role of type I IFN, studies in human SjS are relatively well done.

Current trends in autoimmune diseases are focusing on innate immunity, which acts as a trigger on multiple autoimmune diseases [19]. Type I IFN will be produced as a consequence of the development of innate immunity. High values of type I IFN are rapidly produced in viral infection [81], but also in autoimmune diseases such as SLE [82]. Serum levels of type I IFN were found to be high in pSjS patients compared with normal individuals reported by some groups $[83,84]$, but not by others [85]. Other than role of type I IFN, the central role of B cell-activating factor (BAFF), which promotes B-cell survival and exists in a membrane bound and a secreted form, has been reported in $\mathrm{pSjS}$ [86]. BAFF production and its mRNA expression by cultured human minor salivary gland (HSG) epithelial cells obtained from $\mathrm{pSjS}$ patients can be upregulated after stimulation by chemical TRLs agonist (Poly I:C) or viruses such as reovirus type1 through pathways dependent on Tolllike receptors (TRLs) and independent of type I IFN [86]. Moreover, in systemic autoimmune diseases such as SLE environmental factors (e.g., viral infections), and apoptotic bodies and immune complexes stimulate pDCs through coengagement of the TLRs and $\mathrm{Fc} \gamma$ receptor, resulting in the production of type I IFN from pDCs. Thereafter, type I IFN induces the generation of immunogenic mature DCs, resulting in suppression of regulatory $\mathrm{T}$ (Treg) cell function, which maintain self-tolerance $[87,88]$.

Alternatively, TLR3 activation associated with type I IFN upregulation led to rapid onset and reversible hyposalivation without glandular inflammation [89], suggesting that salivary gland dysfunction may precede autoimmunity development or represent a separate process in the pathogenesis of SjS. It is reported using global gene expression profiling that locally produced IFN- $\alpha$ is detected at higher levels in acini and endothelial cells compared with controls, but IFN- $\alpha$ is mainly secreted by pDCs, which are found in the salivary glands of $\mathrm{pSjS}$ patients but not in healthy controls [90]. Thus, IFN- $\alpha$ in circulation in $\mathrm{pSjS}$ is argued, since serum IFN- $\alpha$ was detected in very few people with pSjS [55, 91, 92], suggesting increased IFN- $\alpha$ was believed to be a local phenomenon. However, systemic activity of type 1 IFN was demonstrated using peripheral monocytes from $\mathrm{pSjS}$ in which several genes associated with IFN exposure were demonstrated, and serum from patients had an enhanced capacity of inducing those genes in the monocytic cell line, suggesting type 1 IFN activity is not only a local but also a systemic phenomenon and pDC may be a possible source of type 1 IFN in pDC $[55,93]$. Interferon regulatory factor 5(IRF5) and signal transducer and activator of transcription 4 (STAT4) gene polymorphisms in the activation of type I IFN and stimulation of innate immunity in mice resulted in dryness, which preceded inflammation in salivary glands, have been reported [94]. In addition, EBV can lead to innate immunity before the development of autoimmune epithelitis in animal models [87]. If that is the case, there is a possibility that circulating type I IFN in SjS may affect function of lacrimal and salivary glands before the development of inflammation of those organs.

3.4. Complement. Complements may play an important role in acquired immunity in $\mathrm{SjS}$ pathogenesis. Also complements may mediate innate immunity and contribute to pathogenesis of nonimmunologic phases, although their roles are not well investigated in SjS.

SjS patients with systemic extraepithelial manifestations display low serum levels of the complement component C4 [95]. We have reported [96] the presence of IgG2a and $\mathrm{C} 3$ in basement membranes at inflamed areas but also at noninflamed areas in submandibular glands of $\mathrm{B} / \mathrm{WF}_{1}$ mice, suggesting those may affect the function of those organs. Nguyen et al. [97] reported that inactivation of C3 (elimination of the $\mathrm{C} 3$ gene) in the parental C57BL/6.NODAec1Aec2 strain, a congenic strain of the NOD model, resulted in a diminished or total absence of both preclinical and clinical manifestations during the development and onset of disease, including reduced acinar cell apoptosis, reduced levels of caspase-3, lack of leukocyte infiltration of submandibular glands, reduced synthesis of diseaseassociated autoantibodies, maintenance of normal glandular architecture, and retention of normal saliva secretion. In addition, C57BL/6.NOD-Aec1Aec2.C $3^{(--)}$mice, which is the $\mathrm{C} 3$ gene knockout mice, retained some early pathological manifestations, including activation of serine kinases with proteolytic activity for parotid secretory protein. This improvement in the clinical manifestations of SjS-like disease in C57BL/6.NOD-Aec1Aec2.C $3^{(-/)}$mice, apparently a direct consequence of $\mathrm{C} 3$ deficiency, supports a much more important role for complement in the adaptive autoimmune response than previously recognized, possibly also implicating an essential role for innate immunity. Thus, they suggest that C3 can play an equally important role in human SjS disease before onset of clinical disease. The role of compliment components in SjS especially during the preimmune phase related with their injurious actions on components of lacrimal and lacrimal and salivary glands has to be investigated,

3.5. Cytokine. If basic diseases in sSjS precede dacryoadenitis and sialoadenitis, circulating proinflammatory and inflammatory cytokines as a consequence of immune reactions may reach at target organs and they may affect functions of those organs (e.g., capillary, myoepithelium, nervous system, tight junction, and basement membrane) before the development of immune reactions at the local sites. If that is the case, capillary and venular endothelium dysfunction with alteration of basement membranes may lead to the leak of those cytokines from the circulation into the target organs (Figure 1). Thus, in this section, the 
role of proinflammatory cytokines including inflammatory cytokines in SjS pathogenesis will be introduced.

In general, cytokines play a central role in the regulation of immunity and are often found to be dysregulated in SjS [98]. Roescher et al. [99] reviewed that in the salivary glands, saliva, and serum of these patients many proinflammatory cytokines such as IFNs, IL-12, IL-18, TNF- $\alpha$, IL-1 $\beta$, IL-6, and B-cell activating factor are upregulated, whereas antiinflammatory cytokines such as transforming growth factor (TGF) $\beta 1$ are undetectable or are expressed at relatively low levels in SjS, except for IL-10 in SjS. Baturone et al. [100] reported that patients with $\mathrm{pSjS}$ showed significantly increased concentrations of each of the five cytokines (IL- $1 \beta$, IL-6, IL-10, TNF- $\alpha$, and IFN- $\gamma$ ) in serum, when compared with the healthy control group, indicating the existence of an immune activation state. Serum levels of one of these cytokines, IL-6, were correlated with poor quality of life in these individuals. Willeke et al. [101] reported that the number of TNF- $\alpha$ and IL-1 $\beta$, but not IL-6, secreting peripheral blood mononuclear cells (PBMCs) was significantly higher in patients with $\mathrm{pSjS}$ than in controls. Patients with recurrent parotid swelling (RPS) had a significantly increased number of IL- $1 \beta$-secreting PBMCs. Moreover, the number of IL- $1 \beta$ secreting PBMCs correlated with the disease activity with the increased concentration of IgM rheumatoid factor (RF) and IgG RF. Other autoantibodies did not correlate with cytokine secreting PBMCs. The increased systemic secretion of IL- $1 \beta$ and TNF- $\alpha$ in patients with pSjS points to a pathogenic impact of these cytokines in this autoimmune disease. In particular, the correlation of IL- $1 \beta$-secreting PBMCs with RPS and RF production indicates that IL- $1 \beta$ is a crucial regulator in the development of local and systemic disease manifestations. Solomon et al. [102] reported that proinflammatory cytokines in tears are derived from local and systemic origin as follows. Compared with normal subjects, the concentration of IL- $1 \alpha$ and mature IL- $1 \beta$ in the tear fluid was increased, in patients with SjS aqueous tear deficiency. The activity of matrix metalloproteinase (MMP)9, a physiological activator of IL-1, was significantly elevated in the tear fluid compared with normal subjects. Dry eye disease (rosacea-associated meibomian gland disease and $\mathrm{SjS}$ ) is accompanied by an increase in the proinflammatory forms of IL-1 (IL- $1 \alpha$ and mature IL- $1 \beta$ ) and a decrease in the biologically inactive precursor IL- $1 \beta$ in tear fluid. Increased protease activity on the ocular surface may be one of mechanisms by which precursor IL-1 $\beta$ is cleaved to the mature, biologically active form. The conjunctival epithelium appears to be one source of the increased concentration of IL-1 in the tear fluid of patients with dry eye disease. These results suggest that IL-1 may play a key role in the pathogenesis of keratoconjunctivitis sicca. Both biological active factors may affect the function of components in local target organs. Jabs et al. [103] reported that mRNAs for inducible nitric oxide synthase iNOS and TNF- $\alpha$ were detected in the lacrimal glands in significantly greater amounts in both MRL/+ and MRL/lpr mice than in normal BALB/c mice. Both iNOS and TNF- $\alpha$ were detected in normal acinar tissue other than in scattered mononuclear cells throughout the lacrimal glands and in mononuclear cells at the junction of the focal inflammatory infiltrates in both MRL/+ and MRL/lpr mice, suggesting that both NO and TNF- $\alpha$ are potential mediators of lacrimal gland damage in these murine models of SjS. Li et al. [104] reported that cathepsin $\mathrm{H}$ (Ctsh), S (Ctss), and Z (Ctsz) and proinflammatory factors (TNF- $\alpha$, IL-6, IL- $1 \beta$ ) were upregulated at the mRNA level in lacrimal glands of male NOD mice. Increased cathepsin S immunofluorescence was detected in lysosomes and secretory vesicle-like organelles in lacrimal gland acinar cells and CD68-positive infiltrating macrophages in NOD mouse lacrimal gland. Cathepsin S (CATS) and cathepsin H (CATH) activities were significantly higher in lacrimal gland lysate from NOD mouse than in control lysate, and CATS activity was also significantly elevated in tears of NOD mice. These suggest that expression of CATS and CATH increases in parallel with proinflammatory cytokines during the development of autoimmune inflammatory disease in NOD mice. Alternatively, human salivary gland cells can be induced to express HLA-DR mRNA along with other inflammatory cytokine gene expression such as IL- $1 \beta$, TNF- $\alpha$, and IL-6, following stimulation with IFN $-\gamma$ [105]. Furthermore, IFN- $\gamma$ is able to upregulate B7.1, B7.2, and HLA-DR expression in salivary gland epithelial cell lines from SjS patients $[32,106]$. These suggest a possible involvement of IFN- $\gamma$ in triggering the epithelial pathology of salivary gland at a preclinical, asymptomatic phase in NOD mice, and active participation of epithelial cells in the disease process occurs through the expression or upregulation of co-stimulatory molecules for the presentation of antigen to the T-cell or through the upregulation of apoptotic molecules such as FasL to induce apoptosis in the diseased glands. In $\mathrm{B} / \mathrm{WF}_{1}$ mice glomerulonephritis precedes lacrimation and sialoadenitis [107-110] (Figures 1 and 2). Before and during the developmental phase of glomerulonephritis, proinflammatory (e.g., IL- $1 \alpha$, IL-6, and less amounts of TNF- $\alpha$ ) and inflammatory (e.g., IFN- $\gamma$ ) cytokines are circulating in the blood [101-109]. Yamakawa et al. [111] reported that IL-1 $\beta$, TNF- $\alpha$, and IL6 have been implicated in the destruction of parotid gland acinar cells (but not duct cells) in autoimmune sialoadenitis. Yao et al. [112] reported that the intraperitoneal injection of lipopolysaccharide (LPS) induced the expression of mRNAs of IL- $1 \beta$, IL- 6 , and TNF- $\alpha$ in the submandibular gland of $\mathrm{C} 3 \mathrm{H} / \mathrm{HeN}$ mice but not that of $\mathrm{C} 3 \mathrm{H} / \mathrm{HeJ}$ mice, a mutant strain for lacking of Toll-like receptor-4 (TLR-4 $4^{(-)}$mutant). The mRNA levels of these cytokines in the submandibular glands of the wild-type mice increased as early as $3 \mathrm{hr}$ after injection, peaked at 3-6hr, and had decreased again by $24 \mathrm{hr}$. Denervation of the superior cervical trunk and chorda tympani nerve did not diminish the LPS-induced elevation of IL- $1 \beta$ mRNA in the SMG, indicating the irrelevance of the central nervous system in this induction. IL- $1 \beta$ proteins were localized in the secretory granules of granular convoluted tubular (GCT) cells in the submandibular gland, and IL- $1 \beta$ of the same size appeared in the saliva $6 \mathrm{hr}$ after LPS injection in $\mathrm{C} 3 \mathrm{H} / \mathrm{HeN}$ but not in $\mathrm{C} 3 \mathrm{H} / \mathrm{HeJ}$ mice. Also, the amount of IL- $1 \beta$ protein is upregulated in acinar cells prepared from lacrimal glands infiltrated with lymphocytes, suggesting that elevated levels of IL- $1 \beta$, as they occur in SjS exocrine glands, may impair the secretory function of lacrimal glands. 
Cytokines especially proinflammatory cytokines may be involved in dysfunction of salivary and lacrimal glands by directly interfering with the epithelial cells in the glands during the phase of noninflammation other than autoimmune reaction. Moreover, it has been reported that, cytokines in the circulation may affect the function of epithelial cells [113], which may be related with decreased tears and saliva before the development of dacryoadenitis and sialoadenitis. Taken together, production of cytokines may affect function of those organs during the noninflammatory phases in $\mathrm{sSjS}$, including even in $\mathrm{pSjS}$ with lesions of exocrine organs in the immune phase.

3.6. Autonomic Nerve. The functional impairment of exocrine glands could be regulated by cytokines and/or antibodies against the muscarinic $\mathrm{M} 3$ receptor by inhibiting the neural stimulation of the residual glands as described already. Autonomic nervous system (ANS) abnormalities are common in Sjögren's syndrome in the immune reaction [114-117] and may play an etiologic role in its pathogenesis. Fatigue, another prominent feature of $\mathrm{SjS}$, has also been associated with ANS dysfunction [118].

The complexity of the ANS along with differences in methodology and studied populations has resulted in variable results, but abnormalities in SjS have been reported both in sympathetic and parasympathetic ANS domains with prevalence as high as $90 \%$ [114]. Zoukhri et al. found that the lymphocytic infiltration of the lacrimal and salivary glands did not alter the parasympathetic, sympathetic, and sensory innervation of the remaining epithelial cells in these tissues in model mice [119]. Barendregt et al. [118] have confirmed the presence of cardiovascular autonomic abnormalities and identified a cluster of subjective autonomic self-reported symptoms associated with fatigue and salivary gland dysfunction. The functional impairment of exocrine glands could be regulated by antibodies against the muscarinic M3 receptor by inhibiting the neuronal stimulation of the residual glands [120] including the possible effects of cytokines in both pSjS and pSjS. Taking a consideration of decreased vascular responses to salivary gland stimulation in SjS patients, Berggreen et al. [121] demonstrated maximal blood flow responses to parasympathetic stimulation and muscarinic receptor activation were significantly lower in NOD mice compared with BALB/c mice, coinciding with impaired saliva secretion in NOD mice, and reduced nitric oxide signaling after parasympathetic nerve stimulation may contribute in part to the impaired blood flow responses. Pedersen et al. [122] reported that the hyposalivation observed in NOD mice may, at least in part, be due to a general loss of neurotransmitter responsiveness in salivary glands. This important finding suggests that genetic defects may be responsible for decrease in saliva production other than destruction of salivary glands by immunologic attacks. Impaired neurotransmitter release in salivary glands in the MRL/lpr mouse has also been reported [123]. In addition, patients with SjS have elevated salivary levels of vasoactive intestinal peptide (VIP) and neuropeptide Y (NPY), which are mainly found in parasympathetic and sympathetic nerves, respectively. This finding indicates increased release of VIP and NPY by salivary glands of SjS patients [124].

Humphreys-Beher et al. [125] reported that tear and salivary flow involves an entire functional system that includes the mucosal surfaces with adnexes (the site of inflammation), efferent nerve signals sent to the midbrain (lacrimal and salivary response region), and afferent neural signals from the brain to the acinar/ductal epithelial structures in the gland. In addition, the electron-microscopic examinations showed that the nerve fibres were in close association to the secretory cells, to the smooth muscle cells of blood vessels, and to the immuno-competent cells. Among several possible extraglandular manifestations, involvement of the peripheral nervous system may occur with reported frequencies from $10 \%$ to $60 \%$ in pSjS [126]. Regarding the role of circulating cytokines, Zoukhri et al. [113] reported that proinflammatory cytokines such as recombinant human (rh) IL- $1 \alpha$, rhIL-1 $\beta$, and rhTNF- $\alpha$ inhibit neurally mediated lacrimal gland secretion in normal $\mathrm{BALB} / \mathrm{c}$ mice in vitro and in vivo, suggesting there can be various extraglandular complication. Taken together, circulating cytokines in sSjS before the development of inflammation may affect extraglandular nervous system other than function of lacrimal and salivary glands.

3.7. Tight Junction. The components of tight junction ( $\mathrm{Tj}$ ) such as ZO-1 and occluding are involved in the pathogenesis in SjS, and cytokines may affect not only in their expression but also in morphological changes. Cytokines influence the function and morphology of tight junction of acinus epithelial cells in the process of inflammation. If that is the case, changes of tight junction will be induced during the noninflammatory phase in SjS especially in sSjS.

Ewert et al. [127] reported significant differences in tight junction protein levels in patients with SjS in relation with proinflammatory cytokines as follows. ZO-1 and occludin were strongly downregulated, while claudin-1 and claudin4 were overexpressed in SjS and tight junction proteins localized exclusively to apical domains in acini and ducts of labial salivary glands (LSGs) from controls. In SjS patients, the ZO-1 and occludin the apical domain presence was decreased, while claudin- 3 and claudin- 4 were redistributed to the basolateral plasma membrane. Exposure of isolated control acini to TNF- $\alpha$ and IFN- $\gamma$ reproduced these alterations in vitro. Moreover, ultrastructural analysis associated tight junction disorganization with the presence of endocytic vesicles containing electron-dense material that may represent tight junction components. They indicate that local cytokine production in large salivary glands from $\mathrm{SjS}$ patients may contribute to the secretory gland dysfunction observed in SjS patients by altering tight junction integrity of epithelial cells, thereby decreasing the quality and quantity of saliva.

Baker et al. [128] reported that the production of the proinflammatory cytokines (TNF- $\alpha$ and IFN- $\gamma$ ) is elevated in exocrine glands of patients with SjS in which chronic exposure of polarized rat parotid gland (Par-C10) epithelial cell monolayers to TNF- $\alpha$ and IFN- $\gamma$ decreases transepithelial resistance (TER) and anion secretion. Treatment of Par-C10 cell monolayers with TNF- $\alpha$ and IFN- $\gamma$ increased paracellular permeability to normally impermeable proteins, altered 
cell and TJ morphology, and downregulated the expression of the TJ protein, claudin-1, but not other TJ proteins expressed in Par-C10 cells. They also suggest that cytokine production is an important contributor to secretory dysfunction in SjS by disrupting TJ integrity of salivary epithelium.

3.8. Basement Membrane. The situation of basement membrane (BM) in terms of functional and morphologic changes may be similar to that of tight junction.

Molina et al. [129] reported the changes in the expression of laminin and type IV collagen in the basement membrane of acini and ducts of labial salivary glands from patients with $\mathrm{SjS}$ were more pronounced than in labial salivary glands from control groups. A remarkable characteristic was the disorganization of the basement membrane in the labial salivary glands in SjS. The pattern of immunoreactivity of the basement membrane of other structures (e.g., blood vessels) did not change and invasion of cytotoxic T lymphocytes was only observed in acini and ducts which had a disorganised basement membrane. They concluded that the high state of disorganization of the basal lamina of acini and ducts could allow invasion of cytotoxic T lymphocytes in SjS. This suggests that the changes of basement membranes are the result of immune attack.

On the other hand, preceded changes of the basement membrane (e.g., collagen type IV, proteoglycan, and fibronectin) in the pathogenesis of the inflammation has been demonstrated by McArthur et al. [130]. They demonstrated that the potential roles of the basement membrane proteins, laminin and fibronectin, and the cytoskeletal protein, tubulin, were assessed in the pathogenesis of SjS by comparing their expressions in SjS with normal labial salivary gland tissue. An increase in laminin or a laminin-like substance on salivary ductal epithelia of SjS patients suggests a potential role for laminin in the pathologic mechanism and increased laminin expression as a marker for SjS. The importance of their findings is that expression of components of the basement membrane precedes the immunological events in salivary glands. We reported [131] laminin expression around the ducts was significantly higher in young $\mathrm{B} / \mathrm{WF}_{1}$ mice than that in control (BALB/c and DBA/1) mice. Periductal laminin expression increased in $\mathrm{B} / \mathrm{WF}_{1}$ mice with age. In addition vary late antigen (VLA)-6, which is a ligand for laminin, was expressed by the infiltrating cells. These suggest that precede laminin expression may be responsible for cell infiltration of the submandibular salivary gland other than immune attack. Defilippi et al. [132] reported TNF- $\alpha$ and IL-1 down regulate laminin receptor, suggesting that proinflammatory cytokines may affect laminin receptor expression before the development of inflammation in $\mathrm{SjS}$.

In addition, the acinar basement membrane is abnormal as it lacks laminin $\alpha 1, \alpha 2$ and $\alpha 4$ chains and lack of alpha 1 , which may impair its capability to induce the progenitor cells to differentiate to acinar cells, leading to leading to acinar cell atrophy and ductal cell hyperplasia [19]. Laminin $\alpha 1-$ chain normally induces intercalated duct progenitors to differentiate to acinar cells through integrin $\alpha 1$ ss 1 and $\alpha 2$ ss 1 receptors, and maintenance of acinar cells is impaired in SjS, which is also characterized by low levels of serum and salivary androgens, since androgens normally support salivary gland remodeling by upregulating either laminin $\alpha 1$ chain or its cellular $\alpha 1$ or $\alpha 2$ integrin subunit-containing receptors [133]. Sullivan et al. [134] demonstrated that the meibomian gland is an androgen target organ and that androgen deficiency may promote meibomian gland dysfunction and evaporative dry eye, suggesting that androgen deficiency may be an important etiologic factor in the pathogenesis of evaporative dry eye in women with SjS. As one of these mechanisms, androgen deficiency may be the effect on laminin [133]. Taking together, at first circulating cytokines may affect morphological and functional changes of the BM, and secondly those changes may permit the leak of circulating several humoral factors including cytokines from capillaries by increased permeability. Furthermore, leaked cytokines may affect function of salivary and lacrimal glands (Figures 1-3). In addition, dysfunction of BM by immune attacks seems likely [96].

\section{Conclusions}

The pathogenesis of SjS remains elusive. Environmental, genetic, and hormonal factors may be involved in its pathogenesis (especially as the role of trigger), and in the past, researchers have focused on the immune responses especially T cell-mediated and humoral immunities in the histopathological lesion during the inflammatory phase of SjS [135]. The key question in this review is nonimmune mechanisms relating to dysfunction of lacrimal and salivary glands before the development of acquired immunity. Regarding nonimmune mechanisms, apoptosis/nonapoptosis and abnormal expression/distribution of AQPs may be, at least in part, induced genetically. Alternatively, it has been suggested that genetic defect in production of neurotransmitter may underlay in the pathogenesis of saliva insufficiency [122]. In addition, exogenous environmental factors (viruses and bacteria) may activate innate immunity, resulting in productions of type I IFN and compliments. Circulating proinflammatory cytokines may induce not only dysfunction but also morphological changes at the ultrastructural level of autonomic nerve, tight junction, and basement membrane. The cumulative effects of each factor/change may induce decreased function of lacrimal and salivary glands without inflammation. Regarding this point, this review stressed the importance of changes in microenvironments (niche) [136] within target organs before the inflammatory cell infiltration in $\mathrm{sSjS}$, including even in $\mathrm{pSjS}$ with exocrinopathy.

To clarify the pathogenesis of SjS using animal models is useful as reviewed previously [31]. However, as described here numerous differences exist between mice and humans (the species difference) that suggest mouse studies are not always applicable to human disease. For example, female MRL/lpr, B/WF 1 , NFS/sld, as IQI/jic and aly/aly mice and NOD mice have been studied as the most notable animal models for their resemblance to autoimmune connective tissue diseases[31]. All of these mice show immunological characteristics in common with SjS (e.g., hypergammaglobulinemia, polyclonal B-cell activation, autoantibody production, and mononuclear cell infiltration in the lacrimal and 
salivary glands). Despite heavy infiltrates within the glands, keratoconjunctivitis sicca (dry eyes) and xerostomia (dry mouth), which are the hallmarks of SjS in humans, have been observed in NOD mice, but not MRL/lpr mice [31]. On the other hand, the loss of secretory function at the age of 6 months of age in $\mathrm{B} / \mathrm{WF}_{1}$ mice occur. Concerning NFS/sld mice, secretory dysfunction was observed at 18 months of age, but this may be relating with age. Moreover, functional defect of other models such as IQI/jic and aly/aly mice is not known. These suggest that mouse age and strain used in experiments are an important factor for functional analysis. In addition, the reasons of contradictory results even within the same strain of mice with the same genetic background such as NOD mice are not known. Alternatively, there are morphological and functional differences between salivary and lacrimal glands, between mouse and human, or between salivary glands. Moreover, anesthesia in the examination of lacrimal and salivary glands function in mice, but not in human, may affect the function of those organs. However, these did not deny the usefulness of mouse model, but I would like to stress that extrapolation of the results of the mouse studies to human in autoimmune SjS must be done with caution in each mouse model.

The causes of hypofunction in salivary and lacrimal glands are complex. The future challenge is to distinguish nonimmunologic mechanisms from immunologic mechanisms in target organs in this unique disease. Identification of gene(s) being responsible for nonimmune pathogenesis using gene targeting models is another way [65]. To create an integrated model that can account for salivary and lacrimal glands hypofunction is ideal [66].

\section{Acknowledgments}

The literature review was supported, in part, by a Grant-inAid of the Ministry of Education, Science, Sports and Culture of Japan C (no. 21580362). Also, the author declare that there is no conflict of interests.

\section{References}

[1] P. Porola, M. Laine, L. Virkki, P. Poduval, and Y. T. Konttinen, "The influence of sex steroids on Sjögren's syndrome," Annals of the New York Academy of Sciences, vol. 1108, pp. 426-432, 2007.

[2] K. J. Bolch, W. W. Bluchanan, M. J. Wohl, and J. J. Bunim, "Sjögren's syndrome: clinical, pathological, and serological studies of sixty-two cases," Medicine, vol. 44, pp. 187-231, 1965.

[3] T. E. W. Feltkamp, "Sjogren's syndrome in relation to other autoimmune diseases," Netherlands Journal of Medicine, vol. 40, no. 3, pp. 105-107, 1992.

[4] L. G. Anderson and N. Talal, "The spectrum of benign to malignant lymphoproliferation in Sjögren's syndrome," Clinical and Experimental Immunology, vol. 10, no. 2, pp. 199-221, 1972.

[5] C. P. Mavragani and H. M. Moutsopoulos, "The geoepidemiology of Sjögren's syndrome," Autoimmunity Reviews, vol. 9, no. 5, pp. A305-A310, 2010.
[6] D. I. Mitsias, E. K. Kapsogeorgou, and H. M. Moutsopoulos, "Sjögren's syndrome: why autoimmune epithelitis?" Oral Diseases, vol. 12, no. 6, pp. 523-532, 2006.

[7] I. Nishimori, Y. Yamamoto, K. Okazaki et al., "Identification of autoantibodies to a pancreatic antigen in patients with idiopathic chronic pancreatitis and Sjögren's syndrome," Pancreas, vol. 9, no. 3, pp. 374-381, 1994.

[8] R. H. Scofield, "Genetics of systemic lupus erythematosus and Sjögren's syndrome," Current Opinion in Rheumatology, vol. 21, no. 5, pp. 448-453, 2009.

[9] C. P. Mavragani and H. M. Moutsopoulos, "The geoepidemiology of Sjögren's syndrome," Autoimmunity Reviews, vol. 9, no. 5, pp. A305-A310, 2010.

[10] C. Miceli-Richard, N. Gestermann, M. Ittah et al., "The CGGGG insertion/deletion polymorphism of the IRF5 promoter is a strong risk factor for primary Sjögren's syndrome," Arthritis and Rheumatism, vol. 60, no. 7, pp. 1991-1997, 2009.

[11] C. Miceli-Richard, E. Comets, P. Loiseau, X. Puechal, E. Hachulla, and X. Mariette, "Association of an IRF5 gene functional polymorphism with Sjögren's syndrome," Arthritis and Rheumatism, vol. 56, no. 12, pp. 3989-3994, 2007.

[12] M. Mamtani, J. M. Anaya, W. He, and S. K. Ahuja, "Association of copy number variation in the FCGR3B gene with risk of autoimmune diseases," Genes and Immunity, vol. 11, no. 2, pp. 155-160, 2010.

[13] M. Laine, P. Porola, L. Udby et al., "Low salivary dehydroepiandrosterone and androgen-regulated cysteine-rich secretory protein 3 levels in Sjögren's syndrome," Arthritis and Rheumatism, vol. 56, no. 8, pp. 2575-2584, 2007.

[14] P. Porola, M. Laine, L. Virkki, P. Poduval, and Y. T. Konttinen, "The influence of sex steroids on Sjögren's syndrome," Annals of the New York Academy of Sciences, vol. 1108, pp. 426-432, 2007.

[15] P. Porola, L. Virkki, B. D. Przybyla et al., "Androgen deficiency and defective intracrine processing of dehydroepiandrosterone in salivary glands in Sjögren's syndrome," Journal of Rheumatology, vol. 35, no. 11, pp. 2229-2235, 2008.

[16] D. A. Sullivan, L. Block, and J. D. O. Pena, "Influence of androgens and pituitary hormones on the structural profile and secretory activity of the lacrimal gland," Acta Ophthalmologica Scandinavica, vol. 74, no. 5, pp. 421-435, 1996.

[17] A. G. Tzioufas, J. Tsonis, and H. M. Moutsopoulos, "Neuroendocrine dysfunction in Sjögren's syndrome," NeuroImmunoModulation, vol. 15, no. 1, pp. 37-45, 2008.

[18] Y. T. Konttinen, P. Porola, L. Konttinen, M. Laine, and P. Poduval, "Immunohistopathology of Sjögren's syndrome," Autoimmunity Reviews, vol. 6, no. 1, pp. 16-20, 2006.

[19] N. P. Nikolov and G. G. Illei, "Pathogenesis of Sjögren's syndrome," Current Opinion in Rheumatology, vol. 21, no. 5, pp. 465-470, 2009.

[20] E. Balada, J. Ordi-Ros, and M. Vilardell-Tarrés, "Molecular mechanisms mediated by Human Endogenous Retroviruses (HERVs) in autoimmunity," Reviews in Medical Virology, vol. 19, no. 5, pp. 273-286, 2009.

[21] C. E. Willoughby, K. Baker, S. B. Kaye et al., "Epstein-Barr virus (types 1 and 2) in the tear film in Sjögren's syndrome and HIV infection," Journal of Medical Virology, vol. 68, no. 3, pp. 378-383, 2002.

[22] É. Toussirot and J. Roudier, "Epstein-Barr virus in autoimmune diseases," Best Practice and Research, vol. 22, no. 5, pp. 883-896, 2008. 
[23] P. J. W. Venables and S. P. Rigby, "Viruses in the etiopathogenesis of Sjögren's syndrome," Journal of Rheumatology, vol. 24, no. 50, pp. 3-5, 1997.

[24] D. Moyes, A. Martin, S. Sawcer, N. Temperton, D. Griffiths, and P. Venables, "The distribution of the endogenous retroviruses HERV-K113 and-K115 in health and disease: HERV-K113 as a novel risk factor for Sjögren's syndrome," Genomics, vol. 86, pp. 337-341, 2005.

[25] L.-J. Couderc, M.-F. D’Agay, F. Danon, M. Harzic, C. Brocheriou, and J. P. Clauvel, "Sicca complex and infection with human immunodeficiency virus," Archives of Internal Medicine, vol. 147, pp. 898-901, 1987.

[26] R. Navone, C. Lunardi, R. Gerli et al., "Identification of tear lipocalin as a novel autoantigen target in Sjögren's syndrome," Journal of Autoimmunity, vol. 25, no. 3, pp. 229234, 2005.

[27] L. Francis and A. Perl, "Infection in systemic lupus erythematosus: friend or foe?" International Journal of Clinical Rheumatology, vol. 5, no. 1, pp. 59-74, 2010.

[28] H. Amital, M. Govoni, R. Maya et al., "Role of infectious agents in systemic rheumatic diseases," Clinical and Experimental Rheumatology, vol. 26, no. 1, pp. S27-S32, 2008.

[29] T. Kamradt, R. Göggel, and K. J. Erb, "Induction, exacerbation and inhibition of allergic and autoimmune diseases by infection," Trends in Immunology, vol. 26, no. 5, pp. 260-267, 2005.

[30] C. Vitali, S. Bombardieri, R. Jonsson et al., "Classification criteria for Sjögren's syndrome: a revised version of the European criteria proposed by the American-European Consensus Group," Annals of the Rheumatic Diseases, vol. 61, no. 6, pp. 554-558, 2002.

[31] M. S. Soyfoo, S. Steinfeld, and C. Delporte, "Usefulness of mouse models to study the pathogenesis of Sjögren's syndrome," Oral Diseases, vol. 13, no. 4, pp. 366-375, 2007.

[32] S. Cha, A. B. Peck, and M. G. Humphreys-Beher, "Progress in understanding autoimmune exocrinopathy using the nonobese diabetic mouse: an update," Critical Reviews in Oral Biology and Medicine, vol. 13, no. 1, pp. 5-16, 2002.

[33] C. P. Robinson, J. Cornelius, D. E. Bounous, H. Yamamoto, M. G. Humphreys-Beher, and A. B. Peck, "Characterization of the changing lymphocyte populations and cytokine expression in the exocrine tissues of autoimmune NOD mice," Autoimmunity, vol. 27, no. 1, pp. 29-44, 1998.

[34] M. G. Humphreys-Beher, J. Brayer, S. Yamachika, A. B. Peck, and R. Jonsson, "An alternative perspective to the immune response in autoimmune exocrinopathy: induction of functional quiescence rather than destructive autoaggression," Scandinavian Journal of Immunology, vol. 49, no. 1, pp. 7-10, 1999.

[35] N. Talal, R. A. Sylvester, T. E. Daniels, J. S. Greenspan, and R. C. Williams Jr., "T and B lymphocytes in peripheral blood and tissue lesions in Sjögren's syndrome," Journal of Clinical Investigation, vol. 53, no. 1, pp. 180-189, 1974.

[36] Y. Ohyama, S. Nakamura, G. Matsuzaki et al., "Cytokine messenger RNA expression in the labial salivary glands of patients with Sjögren's syndrome," Arthritis and Rheumatism, vol. 39, no. 8, pp. 1376-1384, 1996.

[37] R. I. Fox, H. I. Kang, D. Ando, J. Abrams, and E. Pisa, "Cytokine mRNA expression in salivary gland biopsies of Sjögren's syndrome," Journal of Immunology, vol. 152, no. 11, pp. 5532-5539, 1994.

[38] D. I. Mitsias, A. G. Tzioufas, C. Veiopoulou et al., "The Th1/Th2 cytokine balance changes with the progress of the immunopathological lesion of Sjögren's syndrome," Clinical and Experimental Immunology, vol. 128, no. 3, pp. 562-568, 2002.

[39] G. E. Katsifis, S. Rekka, N. M. Moutsopoulos, S. Pillemer, and S. M. Wahl, "Systemic and local interleukin-17 and linked cytokines associated with Sjögren's syndrome immunopathogenesis," American Journal of Pathology, vol. 175, no. 3, pp. 1167-1177, 2009.

[40] A. Espinosa, V. Dardalhon, S. Brauner et al., "Loss of the lupus autoantigen Ro52/Trim 21 induces tissue inflammation and systemic autoimmunity by disregulating the IL-23-Th17 pathway," Journal of Experimental Medicine, vol. 206, no. 8, pp. 1661-1671, 2009.

[41] A. Sakai, Y. Sugawara, T. Kuroishi, T. Sasano, and S. Sugawara, "Identification of IL-18 and Th17 cells in salivary glands of patients with Sjögren's syndrome, and amplification of IL-17-mediated secretion of inflammatory cytokines from salivary gland cells by IL-18," Journal of Immunology, vol. 181, no. 4, pp. 2898-2906, 2008.

[42] C. Q. Nguyen, M. H. Hu, Y. Li, C. Stewart, and A. B. Peck, "Salivary gland tissue expression of interleukin-23 and interleukin-17 in Sjögren's syndrome: findings in humans and mice," Arthritis and Rheumatism, vol. 58, no. 3, pp. 734743, 2008.

[43] A. Espinosa, V. Dardalhon, S. Brauner et al., "Loss of the lupus autoantigen Ro52/Trim21 induces tissue inflammation and systemic autoimmunity by disregulating the IL-23-Th17 pathway," Journal of Experimental Medicine, vol. 206, no. 8, pp. 1661-1671, 2009.

[44] R. I. Fox and H. I. Kang, "Pathogenesis of Sjögren's syndrome," Rheumatic Disease Clinics of North America, vol. 18, no. 3, pp. 517-538, 1992.

[45] N. Haneji, H. Hamano, K. Yanagi, and Y. Hayashi, "A new animal model for primary Sjögren's syndrome in NFS/sld mutant mice," Journal of Immunology, vol. 153, no. 6, pp. 2769-2777, 1994.

[46] J. Kino-Ohsaki, I. Nishimori, M. Morita, K. Okazaki, Y. Yamamoto, and S. Onishi, "Serum antibodies to carbonic anhydrase I and II in patients with idiopathic chronic pancreatitis and Sjögren's syndrome," Gastroenterology, vol. 110, no. 5, pp. 1579-1586, 1996.

[47] S. R. Bacman, A. Berra, L. Sterin-Borda, and E. S. Borda, "Human primary Sjögren's syndrome autoantibodies as mediators of nitric oxide release coupled to lacrimal gland muscarinic acetylcholine receptors," Current Eye Research, vol. 17, no. 12, pp. 1135-1142, 1998.

[48] S. Bacman, L. Sterin-Borda, J. J. Camusso, R. Arana, O. Hubscher, and E. Borda, "Circulating antibodies against rat parotid gland M muscarinic receptors in primary Sjögren's syndrome," Clinical and Experimental Immunology, vol. 104, no. 3, pp. 454-459, 1996.

[49] M. G. Warnock and J. A. Goodacre, "Cryptic T-cell epitopes and their role in the pathogenesis of autoimmune diseases," British Journal of Rheumatology, vol. 36, no. 11, pp. 11441150, 1997.

[50] Y. Paranyuk, N. Claros, A. Birzgalis, L. C. Moore, P. R. Brink, and B. Walcott, "Lacrimal gland fluid secretion and lymphocytic infiltration in the NZB/W mouse model of Sjögren's syndrome," Current Eye Research, vol. 23, no. 3, pp. 199-205, 2001.

[51] M. V. Jonsson, N. Delaleu, K. A. Brokstad, E. Berggreen, and K. Skarstein, "Impaired salivary gland function in NOD mice: association with changes in cytokine profile but not 
with histopathologic changes in the salivary gland," Arthritis and Rheumatism, vol. 54, no. 7, pp. 2300-2305, 2006.

[52] U. S. Deshmukh, Y. Ohyama, H. Bagavant, X. Guo, F. Gaskin, and $\mathrm{S}$. M. Fu, "Inflammatory stimuli accelerate Sjögren's syndrome-like disease in (NZB x NZW) $\mathrm{F}_{1}$ mice," Arthritis and Rheumatism, vol. 58, no. 5, pp. 1318-1323, 2008.

[53] C. P. Robinson, H. Yamamoto, A. B. Peck, and M. G. Humphreys-Beher, "Genetically programmed development of salivary gland abnormalities in the NOD (nonobese diabetic)-scid mouse in the absence of detectable lymphocytic infiltration: a potential trigger for sialoadenitis of NOD mice," Clinical Immunology and Immunopathology, vol. 79, no. 1, pp. 50-59, 1996.

[54] F. Rosignoli, V. Roca, R. Meiss, J. Leceta, R. P. Gomariz, and C. P. Leirós, "Defective signalling in salivary glands precedes the autoimmune response in the non-obese diabetic mouse model of sialadenitis," Clinical and Experimental Immunology, vol. 142, no. 3, pp. 411-418, 2005.

[55] M. E. Wildenberg, C. G. van Helden-Meeuwsen, J. P. van de Merwe, H. A. Drexhage, and M. A. Versnel, "Systemic increase in type I interferon activity in Sjögren's syndrome: a putative role for plasmacytoid dendritic cells," European Journal of Immunology, vol. 38, no. 7, pp. 2024-2033, 2008.

[56] M. Voulgarelis and A. G. Tzioufas, "Pathogenetic mechanisms in the initiation and perpetuation of Sjögren's syndrome," Nature Reviews Rheumatology, vol. 6, no. 9, pp. 529-537, 2010.

[57] M. G. Humphreys-Beher, S. Yamachika, H. Yamamoto et al., "Salivary gland changes in the NOD mouse model for Sjögren's syndrome: is there a non-immune genetic trigger?" European Journal of Morphology, vol. 36, no. 2, pp. 247-251, 1998.

[58] L. Kong, C. P. Robinson, A. B. Peck et al., "Inappropriate apoptosis of salivary and lacrimal gland epithelium of immunodeficient NOD-scid mice," Clinical and Experimental Rheumatology, vol. 16, no. 6, pp. 675-681, 1998.

[59] GE. Qi, H. Hua, Y. Gao, Q. Lin, and G. Y. Yu, "Sialoadenitis progression in nonobese diabetic mice and its correlation with expression of apoptosis-associated proteins in salivary glands and serum IgG levels," Chinese Medical Journal, vol. 120, no. 16, pp. 1426-1431, 2007.

[60] M. Ohlsson, K. Skarstein, A. I. Bolstad, A. C. Johannessen, and R. Jonsson, "Fas-induced apoptosis is a rare event in Sjögren's syndrome," Laboratory Investigation, vol. 81, no. 1, pp. 95-105, 2001.

[61] R. I. Fox and T. Maruyama, "Pathogenesis and treatment of Sjögren's syndrome," Current Opinion in Rheumatology, vol. 9, no. 5, pp. 393-399, 1997.

[62] L. J. Dawson, E. A. Field, A. R. Harmer, and P. M. Smith, "Acetylcholine-evoked calcium mobilization and ion channel activation in human labial gland acinar cells from patients with primary Sjögren's syndrome," Clinical and Experimental Immunology, vol. 124, no. 3, pp. 480-485, 2001.

[63] A. M. Pedersen, S. Dissing, J. Fahrenkrug, J. Hannibal, J. Reibel, and B. Nauntofte, "Innervation pattern and $\mathrm{Ca}^{2+}$ signalling in labial salivary glands of healthy individuals and patients with primary Sjogren's syndrome (pSS)," Journal of Oral Pathology and Medicine, vol. 29, no. 3, pp. 97-109, 2000.

[64] S. C. Van Blokland, C. G. Van Helden-Meeuwsen, A. F. Wierenga-Wolf et al., "Apoptosis and apoptosis-related molecules in the submandibular gland of the nonobese diabetic mouse model for Sjögren's syndrome: limited role for apoptosis in the development of sialoadenitis," Lavoratory Investigation, vol. 80, no. 4, pp. 575-585, 2000.
[65] P. Manganelli and P. Fietta, "Apoptosis and Sjögren syndrome," Seminars in Arthritis and Rheumatism, vol. 33, no. 1, pp. 49-65, 2003.

[66] L. J. Dawson, P. C. Fox, and P. M. Smith, "Sjögrens syndrome- - the non-apoptotic model of glandular hypofunction," Rheumatology, vol. 45, no. 7, pp. 792-798, 2006.

[67] L. S. King, M. Yasui, and P. Agre, "Aquaporins in health and disease," Molecular Medicine, vol. 6, no. 2, pp. 60-65, 2000.

[68] C. Delporte and S. Steinfeld, "Distribution and roles of aquaporins in salivary glands," Biochimica et Biophysica Acta, vol. 1758, no. 8, pp. 1061-1070, 2006.

[69] L. Xiao, T. B. Ng, Y. B. Feng et al., "Dendrobium candidum extract increases the expression of aquaporin-5 in labial glands from patients with Sjögren's syndrome," Phytomedicine, vol. 18, no. 2-3, pp. 194-198, 2011.

[70] S. Steinfeld, E. Cogan, L. S. King, P. Agre, R. Kiss, and C. Delporte, "Abnormal distribution of aquaporin-5 water channel protein in salivary glands from Sjögren's syndrome patients," Laboratory Investigation, vol. 81, no. 2, pp. 143148, 2001.

[71] D. Beroukas, J. Hiscock, B. J. Gannon, R. Jonsson, T. P. Gordon, and S. A. Waterman, "Selective down-regulation of aquaporin-1 in salivary glands in primary Sjögren's syndrome," Laboratory Investigation, vol. 82, no. 11, pp. 1547-1552, 2002.

[72] K. Tsubota, S. Hirai, L. S. King, P. Agre, and N. Ishida, "Defective cellular trafficking of lacrimal gland aquaporin-5 in Sjögren's syndrome," Lancet, vol. 357, no. 9257, pp. 688$689,2001$.

[73] D. Beroukas, J. Hiscock, R. Jonsson, S. A. Waterman, and T. P. Gordon, "Subcellular distribution of aquaporin 5 in salivary glands in primary Sjögren's syndrome," Lancet, vol. 358, no. 9296, pp. 1875-1876, 2001.

[74] D. A. Groneberg, C. Peiser, and A. Fischer, "Distribution of salivary aquaporin-5 in Sjögren's syndrome," Lancet, vol. 359, no. 9319, pp. 1778-1779, 2002.

[75] Y. Sasaki, K. Tsubota, J. D. Kawedia, A. G. Menon, and M. Yasui, "The difference of aquaporin 5 distribution in acinar and ductal cells in lacrimal and parotid glands," Current Eye Research, vol. 32, no. 11, pp. 923-929, 2007.

[76] C. M. Krane, J. E. Melvin, HA. V. Nguyen et al., "Salivary acinar cells from aquaporin 5-deficient mice have decreased membrane water permeability and altered cell volume regulation," Journal of Biological Chemistry, vol. 276, no. 26, pp. 23413-23420, 2001.

[77] M. Moore, T. Ma, B. Yang, and A. S. Verkman, "Tear secretion by lacrimal glands in transgenic mice lacking water channels AQP1, AQP3, AQP4 and AQP5," Experimental Eye Research, vol. 70, no. 5, pp. 557-562, 2000.

[78] M. S. Soyfoo, C. De Vriese, H. Debaix et al., "Modified aquaporin 5 expression and distribution in submandibular glands from NOD mice displaying autoimmune exocrinopathy," Arthritis and Rheumatism, vol. 56, no. 8, pp. 2566-2574, 2007.

[79] H. Nishimura, A. Yakeishi, T. Saga, and K. Yamaki, "Effects of cevimeline on the immunolocalization of aquaporin-5 and the ultrastructure of salivary glands in Sjögren's syndrome model mice," Kurume Medical Journal, vol. 56, no. 3-4, pp. 39-47, 2009.

[80] Y. T. Konttinen, E. K. Tensing, M. Laine, P. Porola, J. Törnwall, and M. Hukkanen, "Abnormal distribution of aquaporin-5 in salivary glands in the NOD mouse model for Sjögren's syndrome," Journal of Rheumatology, vol. 32, no. 6, pp. 1071-1075, 2005. 
[81] T. Taniguchi and A. Takaoka, "A weak signal for strong responses: interferon- $\alpha / \beta$ revisited," Nature Reviews Molecular Cell Biology, vol. 2, no. 5, pp. 378-386, 2001.

[82] L. Rönnblom and G. V. Alm, "An etiopathogenic role for the type I IFN system in SLE," Trends in Immunology, vol. 22, no. 8, pp. 427-431, 2001.

[83] J. M. Anaya, R. D. Mantilla, and P. A. Correa, "Immunogenetics of primary Sjögren's syndrome in Colombians," Seminars in Arthritis and Rheumatism, vol. 34, no. 5, pp. 735-743, 2005.

[84] U. Båve, G. Nordmark, T. Lövgren et al., "Activation of the type I interferon system in primary Sjögren's syndrome: a possible etiopathogenic mechanism," Arthritis and Rheumatism, vol. 52, no. 4, pp. 1185-1195, 2005.

[85] P. Oxholm, T. E. Daniels, and K. Bendtzen, "Cytokine expression in labial salivary glands from patients with primary Sjögren's syndrome," Autoimmunity, vol. 12, no. 3, pp. 185-191, 1992.

[86] M. Ittah, C. Miceli-Richard, J. E. Gottenberg et al., "Viruses induce high expression of BAFF by salivary gland epithelial cells through TLR- and type-I IFN-dependent and independent pathways," European Journal of Immunology, vol. 38, no. 4, pp. 1058-1064, 2008.

[87] D. A. Horwitz, S. G. Zheng, J. Wang, and J. D. Gray, "Critical role of IL-2 and TGF- $\beta$ in generation, function and stabilization of Foxp $3^{+} \mathrm{CD} 4^{+}$Treg," European Journal of Immunology, vol. 38, no. 4, pp. 912-915, 2008.

[88] J. Banchereau and V. Pascual, "Type I interferon in systemic lupus erythematosus and other autoimmune diseases," Immunity, vol. 25, no. 3, pp. 383-392, 2006.

[89] U. S. Deshmukh, S. R. Nandula, P. R. Thimmalapura, Y. M. Scindia, and H. Bagavant, "Activation of innate immune responses through Toll-like receptor 3 causes a rapid loss of salivary gland function," Journal of Oral Pathology and Medicine, vol. 38, no. 1, pp. 42-47, 2009.

[90] J. E. Gottenberg, N. Cagnard, C. Lucchesi et al., "Activation of IFN pathways and plasmacytoid dendritic cell recruitment in target organs of primary Sjögren's syndrome," Proceedings of the National Academy of Sciences of the United States of America, vol. 103, no. 8, pp. 2770-2775, 2006.

[91] N. M. Moutsopoulos, G. E. Katsifis, N. Angelov et al., "Lack of efficacy of etanercept in Sjögren syndrome correlates with failed suppression of tumour necrosis factor $\alpha$ and systemic immune activation," Annals of the Rheumatic Diseases, vol. 67, no. 10, pp. 1437-1443, 2008.

[92] S. Shiozawa, K. Shiozawa, S. Shimizu et al., "Immunoreactive circulating alpha-interferon is low in Sjögren's syndrome," British Journal of Rheumatology, vol. 29, no. 1, pp. 50-52, 1990.

[93] T. B. Niewold, T. L. Rivera, J. P. Buyon, and M. K. Crow, "Serum type I interferon activity is dependent on maternal diagnosis in anti-SSA/Ro-positive mothers of children with neonatal lupus," Arthritis and Rheumatism, vol. 58, no. 2, pp. 541-546, 2008.

[94] X. Mariette and J. E. Gottenberg, "Pathogenesis of Sjögren's syndrome and therapeutic consequences," Current Opinion of Rheumatology, vol. 22, no. 5, pp. 471-477, 2010.

[95] M. Voulgarelis and A. G. Tzioufas, "Pathogenetic mechanisms in the initiation and perpetuation of Sjögren's syndrome," Nature Reviews Rheumatology, vol. 6, no. 9, pp. 529-537, 2010.

[96] T. Hayashi, H. Hayashi, T. Fujii, C. Adachi, and K. Hasegawa, "Ultrastructure of myoepithelial cells as a target cell in sialoadenitis of submandibular glands of lupus-prone female $\mathrm{NZBXNZWF}_{1}$ mice," Virchows Archiv, vol. 453, no. 2, pp. 177-188, 2008.

[97] C. Q. Nguyen, H. Kim, J. G. Cornelius, and A. B. Peck, "Development of Sjögren's syndrome in nonobese diabeticderived autoimmune-prone C57BL/6.NOD-Aec1Aec2 mice is dependent on complement component-3," Journal of Immunology, vol. 179, no. 4, pp. 2318-2329, 2007.

[98] P. Szodoray, P. Alex, J. G. Brun, M. Centola, and R. Jonsson, "Circulating cytokines in primary Sjögren's syndrome determined by a multiplex cytokine array system," Scandinavian Journal of Immunology, vol. 59, no. 6, pp. 592-599, 2004.

[99] N. Roescher, P. P. Tak, and G. G. Illei, "Cytokines in Sjögren's syndrome,” Oral Diseases, vol. 15, no. 8, pp. 519-526, 2009.

[100] R. Baturone, M. J. Soto, M. Márquez et al., "Healthrelated quality of life in patients with primary Sjögren's syndrome: relationship with serum levels of proinflammatory cytokines," Scandinavian Journal of Rheumatology, vol. 38, no. 5, pp. 386-389, 2009.

[101] P. Willeke, H. Schotte, B. Schlüter et al., "IL-1beta and TNF alpha secreting cells are increased in the peripheral blood of patients with primary Sjögren's syndrome," Annals of Rheumatic Diseases, vol. 62, no. 4, pp. 359-362, 2003.

[102] A. Solomon, D. Dursun, Z. Liu, Y. Xie, A. Macri, and S. C. Pflugfelder, "Pro- and anti-inflammatory forms of interleukin-1 in the tear fluid and conjunctiva of patients with dry-eye disease," Investigative Ophthalmology and Visual Science, vol. 42, no. 10, pp. 2283-2292, 2001.

[103] D. A. Jabs, H. C. Gérard, Y. Wei et al., "Inflammatory mediators in autoimmune lacrimal gland disease in MRL/Mpj mice," Investigative Ophthalmology and Visual Science, vol. 45, no. 7, pp. 2293-2298, 2004.

[104] X. Li, K. Wu, M. Edman et al., "Increased expression of cathepsins and obesity-induced pro-inflammatory cytokines in lacrimal glands of male NOD mouse," Investigative Ophthalmology \& Visual Science, vol. 51, no. 10, pp. 50195029,2010

[105] H. Hamano, N. Haneji, K. Yanagi, N. Ishimaru, and Y. Hayashi, "Expression of HLA-DR and cytokine genes on interferon- $\gamma$-stimulated human salivary gland cell line," Pathobiology, vol. 64, no. 5, pp. 255-261, 1996.

[106] M. N. Manoussakis, I. D. Dimitriou, E. K. Kapsogeorgou et al., "Expression of B7 costimulatory molecules by salivary gland epithelial cells in patients with Sjögren's syndrome," Arthritis and Rheumatism, vol. 42, no. 2, pp. 229-239, 1999.

[107] T. Hayashi, K. Hasegawa, and C. Adachi, "Elimination of $\mathrm{CD} 4{ }^{+} \mathrm{CD} 25^{+} \mathrm{T}$ cell accelerates the development of glomerulonephritis during the preactive phase in autoimmuneprone female NZBxNZWF1 mice," Intenational Journal of Experimental Pathology, vol. 86, no. 5, pp. 289-296, 2005.

[108] T. Hayashi, C. Adachi, and K. Hasegawa, "Systemic treatment of anti-CD $4^{+} \mathrm{CD} 25^{+} \mathrm{T}$ cell monoclonal antibody exacerbates sialoadenitis in submandibular glands during the early life in lupus-prone female NZB $\times \mathrm{NZWF}_{1}$ mice," Journal of Oral Pathology and Medicine, vol. 38, no. 2, pp. 234-240, 2009.

[109] T. Hayashi, K. Hasegawa, and N. Ichinohe, "ICAM-1 expression on endothelium and systemic cytokine production in cutaneous neutrophilic leucocytoclastic vasculitis in $\mathrm{NZBXNZWF}_{1}$ mice," Histology and Histopathology, vol. 20, no. 1, pp. 45-52, 2005.

[110] K. Hasegawa and T. Hayashi, "Synthetic CpG oligodeoxynucleotides accelerate the development of lupus nephritis during preactive phase in NZB $\times \mathrm{NZWF}_{1}$ mice," Lupus, vol. 12, no. 11, pp. 838-845, 2003. 
[111] M. Yamakawa, R. Weinstein, T. Tsuji, J. McBride, D. T. W. Wong, and G. R. Login, "Age-related alterations in IL- $1 \beta$, TNF- $\alpha$, and IL- 6 concentrations in parotid acinar cells from BALB/c and non-obese diabetic mice," Journal of Histochemistry and Cytochemistry, vol. 48, no. 8, pp. 1033$1041,2000$.

[112] C. Yao, X. Li, K. Murdiastuti et al., "Lipopolysaccharideinduced elevation and secretion of interleukin- $1 \beta$ in the submandibular gland of male mice," Immunology, vol. 116, no. 2, pp. 213-222, 2005.

[113] D. Zoukhri, R. R. Hodges, D. Byon, and C. L. Kublin, "Role, of proinflammatory cytokines in the impaired lacrimation associated with autoimmune xerophthalmia," Investigative Ophthalmology and Visual Science, vol. 43, no. 5, pp. 14291436, 2002.

[114] A. P. Andonopoulos, J. Christodoulou, C. Ballas, A. Bounas, and D. Alexopoulos, "Autonomic cardiovascular neuropathy in Sjögren's syndrome. A controlled study," Journal of Rheumatology, vol. 25, no. 12, pp. 2385-2388, 1998.

[115] F. Z. J. Cai, S. Lester, T. Lu et al., "Mild autonomic dysfunction in primary Sjögren's syndrome: a controlled study," Arthritis Research and Therapy, vol. 10, no. 2, article R31, 2008.

[116] L. Kovacs, M. Papos, R. Takacs et al., "Autonomic nervous system dysfunction involving the gastrointestinal and the urinary tracts in primary Sjögren's syndrome," Clinicla Experimental Rheumatology, vol. 21, pp. 697-703, 2003.

[117] T. Mandl, V. Granberg, J. Apelqvist, P. Wollmer, R. Manthorpe, and L. T. H. Jacobsson, "Autonomic nervous symptoms in primary Sjögren's syndrome," Rheumatology, vol. 47, no. 6, pp. 914-919, 2008.

[118] P. J. Barendregt, M. R. M. Visser, E. M. A. Smets et al., "Fatigue in primary Sjögren's syndrome," Annals of the Rheumatic Diseases, vol. 57, no. 5, pp. 291-295, 1998.

[119] D. Zoukhri and C. L. Kublin, "Impaired neurotransmitter release from lacrimal and salivary gland nerves of a murine model of Sjögren's syndrome," Investigative Ophthalmology and Visual Science, vol. 42, no. 5, pp. 925-932, 2001.

[120] T. P. Gordon, A. I. Bolstad, M. Rischmueller, R. Jonsson, and S. A. Waterman, "Autoantibodies in primary Sjögren's syndrome: new insights into mechanisms of autoantibody diversification and disease pathogenesis," Autoimmunity, vol. 34, no. 2, pp. 123-132, 2001.

[121] E. Berggreen, K. Nyløkken, N. Delaleu, H. HajdaragicIbricevic, and M. V. Jonsson, "Impaired vascular responses to parasympathetic nerve stimulation and muscarinic receptor activation in the submandibular gland in nonobese diabetic mice," Arthritis Research and Therapy, vol. 11, no. 1, article R18, 2009.

[122] A. M. Pedersen, S. Dissing, J. Fahrenkrug, J. Hannibal, J. Reibel, and B. Nauntofte, "Innervation pattern and $\mathrm{Ca}^{2+}$ signalling in labial salivary glands of healthy individuals and patients with primary Sjögren's syndrome (pSS)," Journal of Oral Pathology and Medicine, vol. 29, no. 3, pp. 97-109, 2000.

[123] D. Zoukhri and C. L. Kublin, "Impaired neurotransmitter release from lacrimal and salivary gland nerves of a murine model of Sjögren's syndrome," Investigative Ophthalmolology Visual Science, vol. 42, no. 5, pp. 925-932, 2001.

[124] N. Santavirta, Y. T. Konttinen, J. Törnwall et al., "Neuropeptides of the autonomic nervous system in Sjögren's syndrome," Annals of the Rheumatic Diseases, vol. 56, no. 12, pp. 737-740, 1997.

[125] M. G. Humphreys-Beher, J. Brayer, S. Yamachika, A. B. Peck, and R. Jonsson, "An alternative perspective to the immune response in autoimmune exocrinopathy: induction of functional quiescence rather than destructive autoaggression," Scandinavian Journal of Immunology, vol. 49, no. 1, pp. 7-10, 1999.

[126] S. I. Mellgren, L. G. Göransson, and R. Omdal, "Primary Sjögren's syndrome associated neuropathy," Canadian Journal of Neurological Sciences, vol. 34, no. 3, pp. 280-287, 2007.

[127] P. Ewert, S. Aguilera, C. Alliende et al., "Disruption of tight junction structure in salivary glands from Sjögren's syndrome patients is linked to proinflammatory cytokine exposure," Arthritis and Rheumatism, vol. 62, no. 5, pp. 1280 $1289,2010$.

[128] O. J. Baker, J. M. Camden, R. S. Redman et al., "Proinflammatory cytokines tumor necrosis factor- $\alpha$ and interferon- $\gamma$ alter tight junction structure and function in the rat parotid gland Par-C10 cell line," American Journal of Physiology, vol. 295, no. 5, pp. C1191-C1201, 2008.

[129] C. Molina, C. Alliende, S. Aguilera et al., "Basal lamina disorganisation of the acini and ducts of labial salivary glands from patients with Sjögren's syndrome: association with mononuclear cell infiltration," Annals of Rhematic Diseases, vol. 65 , no. 2, pp. 178-183, 2006.

[130] C. P. McArthur, N. W. Fox, and P. Kragel, "Monoclonal antibody detection of laminin in minor salivary glands of patients with Sjögren's Syndrome," Journal of Autoimmunity, vol. 6, no. 5, pp. 649-661, 1993.

[131] T. Hayashi, T. Shirachi, and K. Hasegawa, "Relationship between sialoadenitis and periductal laminin expression in the submandibular salivary gland of $\mathrm{NZBxNZWF}_{1}$ mice," Journal of Comparative Pathology, vol. 125, no. 2-3, pp. 110116, 2001.

[132] P. Defilippi, L. Silengo, and G. Tarone, "Alpha 6.beta 1 integrin (laminin receptor) is down-regulated by tumor necrosis factor alpha and interleukin-1 beta in human endothelial cells," Journal of Biological Chemistry, vol. 267, no. 26, pp. 18303-18307, 1992.

[133] P. Porola, M. Laine, I. Virtanen, R. Pöllänen, B. D. Przybyla, and Y. T. Konttinen, "Androgens and integrins in salivary glands in Sjögren's syndrome," Journal of Rheumatology, vol. 37, no. 6, pp. 1181-1187, 2010.

[134] D. A. Sullivan, B. D. Sullivan, J. E. Evans et al., "Androgen deficiency, meibomian gland dysfunction, and evaporative dry eye," Annals of the New York Academy of Sciences, vol. 966, pp. 211-222, 2002.

[135] L. Kovács, T. Török, F. Bari et al., "Impaired microvascular response to cholinergic stimuli in primary Sjögren's syndrome," Annals of the Rheumatic Diseases, vol. 59, no. 1, pp. 48-53, 2000.

[136] T. Hayashi, "Environmental factors and concepts in the induction of type 1 diabetes," in Hand book of Type 1 Diabetes Mellitus, T. Hayashi, Ed., pp. 1-54, Nova Science, 2010. 


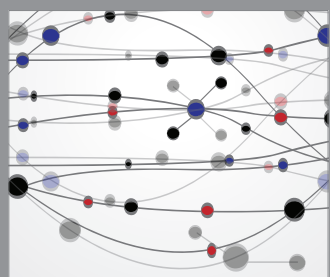

The Scientific World Journal
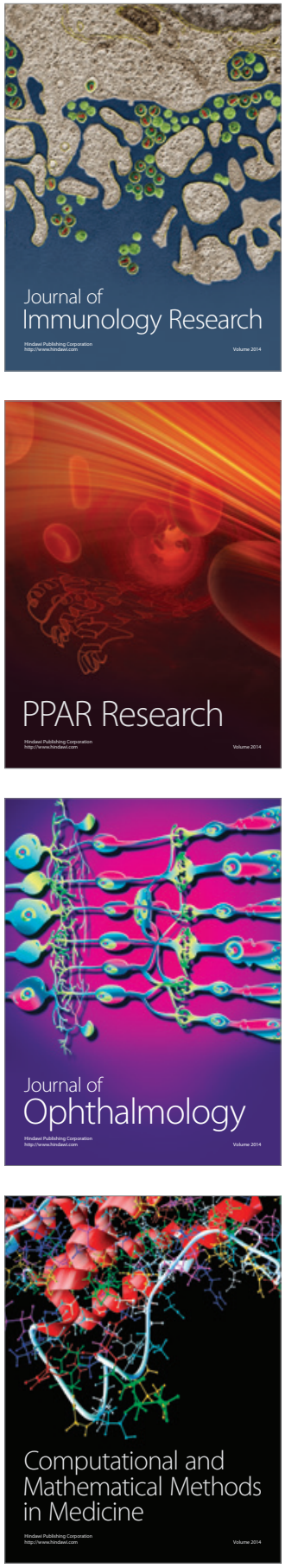

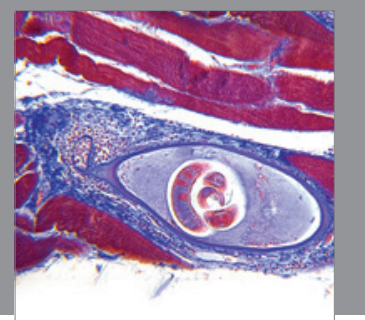

Gastroenterology

Research and Practice
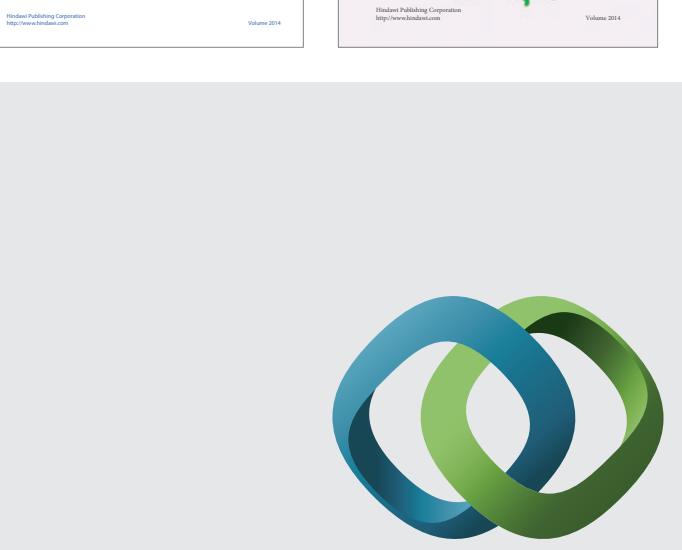

\section{Hindawi}

Submit your manuscripts at

http://www.hindawi.com
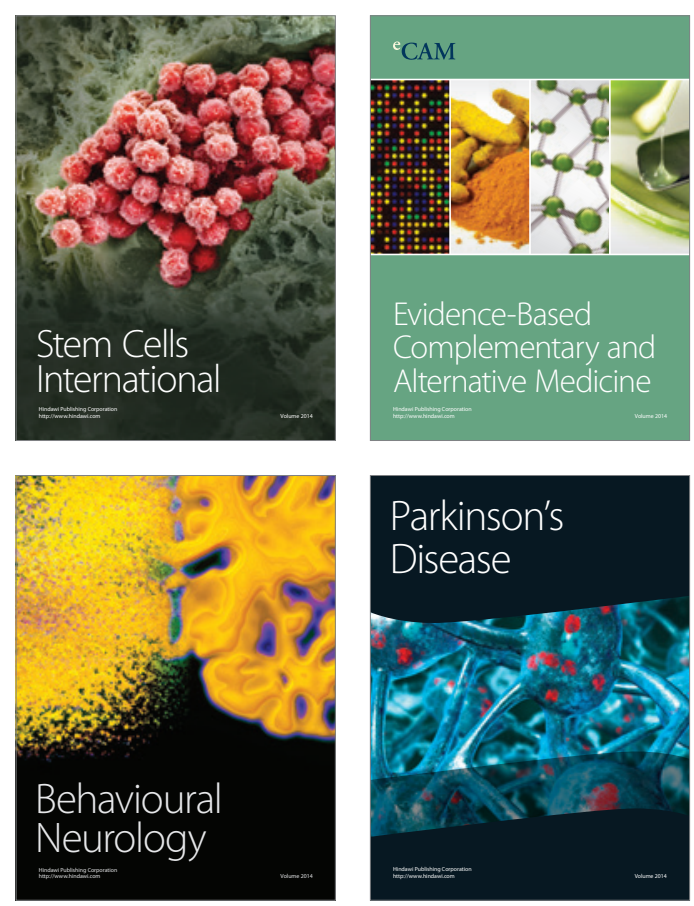

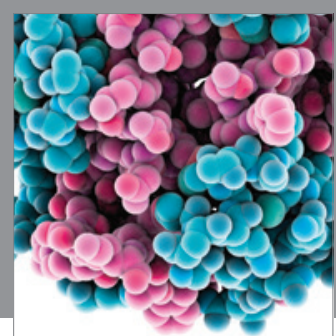

Journal of
Diabetes Research

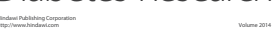

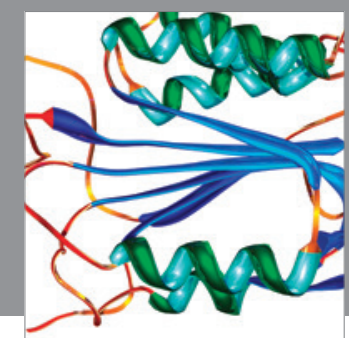

Disease Markers
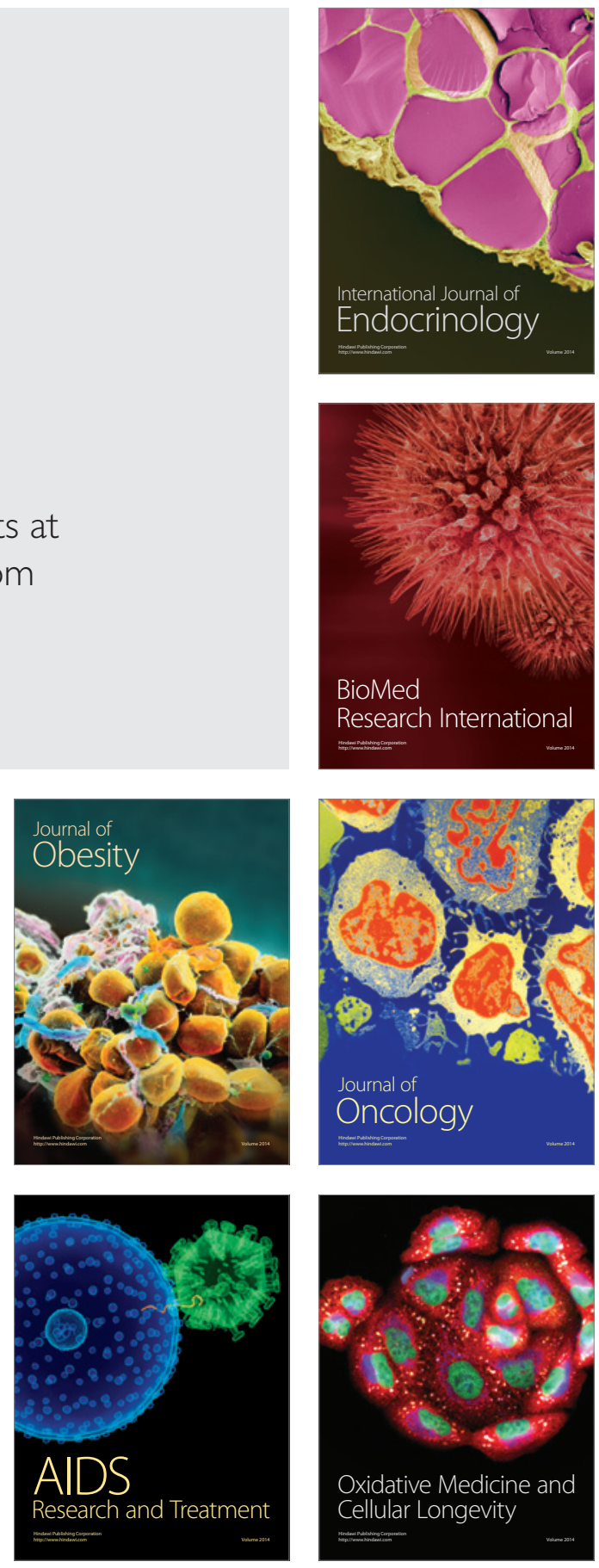